\title{
Framework for developing volcanic fragility and vulnerability functions for critical infrastructure
}

\author{
Grant Wilson ${ }^{1,2}$, Thomas M. Wilson ${ }^{1 *}$, Natalia I. Deligne ${ }^{3}$, Daniel M. Blake ${ }^{1}$ and Jim W. Cole
}

\begin{abstract}
Volcanic risk assessment using probabilistic models is increasingly desired for risk management, particularly for loss forecasting, critical infrastructure management, land-use planning and evacuation planning. Over the past decades this has motivated the development of comprehensive probabilistic hazard models. However, volcanic vulnerability models of equivalent sophistication have lagged behind hazard modelling because of the lack of evidence, data and, until recently, minimal demand. There is an increasingly urgent need for development of quantitative volcanic vulnerability models, including vulnerability and fragility functions, which provide robust quantitative relationships between volcanic impact (damage and disruption) and hazard intensity. The functions available to date predominantly quantify tephra fall impacts to buildings, driven by life safety concerns.

We present a framework for establishing quantitative relationships between volcanic impact and hazard intensity, specifically through the derivation of vulnerability and fragility functions. We use tephra thickness and impacts to key infrastructure sectors as examples to demonstrate our framework. Our framework incorporates impact data sources, different impact intensity scales, preparation and fitting of data, uncertainty analysis and documentation. The primary data sources are post-eruption impact assessments, supplemented by laboratory experiments and expert judgment, with the latter drawing upon a wealth of semi-quantitative and qualitative studies. Different data processing and function fitting techniques can be used to derive functions; however, due to the small datasets currently available, simplified approaches are discussed. We stress that documentation of data processing, assumptions and limitations is the most important aspect of function derivation; documentation provides transparency and allows others to update functions more easily. Following our standardised approach, a volcanic risk scientist can derive a fragility or vulnerability function, which then can be easily compared to existing functions and updated as new data become available.

To demonstrate how to apply our framework, we derive fragility and vulnerability functions for discrete tephra fall impacts to electricity supply, water supply, wastewater and transport networks. These functions present the probability of an infrastructure site or network component equalling or exceeding one of four impact states as a function of tephra thickness.
\end{abstract}

Keywords: Tephra fall, Volcano, Risk, Hazard, Critical infrastructure, Electricity, Water supply, Wastewater, Transportation

\footnotetext{
*Correspondence: thomas.wilson@canterbury.ac.nz

'Department of Geological Sciences, University of Canterbury, Private Bag

4800, Christchurch 8140, New Zealand

Full list of author information is available at the end of the article
} 


\section{Introduction}

Volcanic eruptions are multi-hazard events which pose a considerable threat to society, including critical infrastructure (Wilson et al. 2012a; Cottrell 2014; Wilson et al. 2014). Critical infrastructure such as electricity supply, water supply and wastewater, transportation, communications and associated buildings, are man-made systems and processes which function together to deliver essential services to society (Rinaldi et al. 2001). Disruption or damage to critical infrastructure can cause significant societal impacts and economic losses. To reduce critical infrastructure losses during volcanic eruptions, successful risk assessment and management - a combination of hazard, exposure and vulnerability assessments - is required. Robust quantitative probabilistic volcanic risk models are increasingly desirable for volcanic risk management, particularly for loss forecasting, infrastructure management and land-use planning. This has driven the development of sophisticated probabilistic hazard models (e.g., Schilling 1998; Bonadonna 2006; Costa et al. 2006; Del Negro et al. 2008; Wadge 2009). However, vulnerability models have lagged considerably and there is now an increasingly urgent need for quantitative vulnerability assessment of volcanic hazard impacts. Quantitative vulnerability assessments are available for buildings (e.g., Spence et al. 2005; Zuccaro et al. 2008; Jenkins and Spence 2009; Jenkins et al. 2014a), primarily driven by occupant life safety concerns. For critical infrastructure there are a number of qualitative/semi-quantitative assessments (e.g., Patterson 1987; Johnston and Nairn 1993; Daly and Wilkie 1999; Wilson et al. 2012a; Jenkins et al. 2014b; Wilson et al. 2014) however, quantitative vulnerability assessments are lacking. To address the need for comprehensive quantitative volcanic vulnerability assessments for all infrastructure sectors, a framework is required to guide volcanic risk scientists through the process of deriving vulnerability estimates.

The aim of this paper is to present a framework for deriving quantitative relationships between hazard intensity (e.g., tephra thickness, flow dynamic pressure) and damage, disruption or other impact metrics to infrastructure components or sectors from volcanic hazards. The focus is on the derivation of fragility and vulnerability functions as these are the most appropriate way to express infrastructure vulnerability and are widely used in other natural hazard fields (e.g., Porter et al. 2007). In section Volcanic Vulnerability Assessment Approaches we introduce vulnerability and fragility functions and briefly review currently published functions for volcanic vulnerability assessments. In section Volcanic Vulnerability and Fragility Framework we present a framework for the derivation of fragility and vulnerability functions focusing on input data, impact and hazard intensity metrics, function fitting, uncertainty analysis and documentation. The framework is designed to evolve when new data becomes available and is recorded in different forms. In section Volcanic Tephra Fall Fragility Functions we demonstrate application of the framework through the derivation of fragility functions for electricity, water supply, wastewater treatment, and transportation networks impacted by tephra fall. These functions are a first attempt at quantifying vulnerability of critical infrastructure sectors for tephra fall impacts and should be updated (e.g., calibration, adjust function fitting, improve uncertainty assessment) when new volcanic impact data become available. We also suggest that the framework is transferable to other assets such as people or agriculture. However, impacts to these assets are highly spatially dependent (e.g. due to specific societal and climatic factors respectively) and application should be approached cautiously due to limited impact data in some locations. Finally, in Conclusions we summarise the main contributions of our paper and discuss future research priorities emerging from this work and the wider field.

\section{Volcanic vulnerability assessment approaches}

There are a number of qualitative and quantitative approaches that can be used to assess the vulnerability of exposed elements to volcanic hazards (Table 1). Use of qualitative descriptions of volcanic hazard impacts to different exposed elements forms an important foundation of volcanic impact knowledge. These qualitative descriptions are defined based on documentation and reviews of impacts from previous eruptions (e.g., Blong 1984; Spence et al. 1996; Blong 2003a; Baxter et al. 2005; Stewart et al. 2006; Wilson et al. 2012a; Jenkins et al. 2013, 2014a; Wilson et al. 2014). This knowledge has been successfully used for volcanic risk management, such as informing emergency management exercises, development of public and sector specific information resources and some risk assessments (Wilson et al. 2014).

While qualitative descriptions of impacts is informative, a move towards quantification of impacts is required to facilitate robust numerical estimation of risk (Wilson et al. 2012a; Jenkins et al. 2014b; Wilson et al. 2014; Brown et al. 2015). Risk quantification allows for comparisons between infrastructure sites/networks and with other natural hazard risks; it provides a basis for cost-benefit analysis of mitigation strategies. Impact state (IS) scales and threshold levels can be used to categorise qualitative impact data (Blong 2003b), providing a semiquantitative assessment of impact to infrastructure sites.

Fully quantitative vulnerability assessment requires fragility and vulnerability functions. Rossetto et al. (2013) and Tarbotton et al. (2015) define these function types as:

1. Vulnerability functions quantify a component's mean damage or function loss as a value relative to total impact or as an economic cost as a function of hazard intensity. 
Table 1 Description, examples, advantages and disadvantages of different types of vulnerability assessments for volcanic hazards. Note that the advantages and disadvantages refer to the example implementation of the vulnerability assessments, not the approaches themselves

\begin{tabular}{|c|c|c|c|c|}
\hline Name & Description & Implementation example & Advantages & Disadvantages \\
\hline $\begin{array}{l}\text { Qualitative } \\
\text { descriptions }\end{array}$ & $\begin{array}{l}\text { Qualitative description of } \\
\text { probable impacts to } \\
\text { infrastructure based upon the } \\
\text { presence of a volcanic hazard. }\end{array}$ & $\begin{array}{l}\text { Review and documentation of } \\
\text { critical infrastructure impacts } \\
\text { from historic eruptions (Wilson et } \\
\text { al. 2012a; Wilson et al. 2014). }\end{array}$ & $\begin{array}{l}\text { Detailed explanation of likely } \\
\text { impacts and vulnerabilities } \\
\text { for each infrastructure sector, } \\
\text { highlighting potential } \\
\text { mitigation strategies. }\end{array}$ & $\begin{array}{l}\text { No indication of the differing } \\
\text { levels of vulnerability at a } \\
\text { particular site. } \\
\text { Difficult to compare multiple } \\
\text { locations. } \\
\text { No spatial extent of } \\
\text { vulnerability. }\end{array}$ \\
\hline $\begin{array}{l}\text { Vulnerability } \\
\text { indicators }\end{array}$ & $\begin{array}{l}\text { Vulnerability indicators are an } \\
\text { attribute or property of a system } \\
\text { which influences vulnerability or } \\
\text { resilience to volcanic hazards. } \\
\text { The degree to which this } \\
\text { attribute influences vulnerability } \\
\text { can be expressed qualitatively } \\
\text { (e.g. high, medium, low) or with }\end{array}$ & $\begin{array}{l}\text { Infrastructure vulnerability } \\
\text { indicators to assess vulnerability } \\
\text { to volcanic hazards on Vulcano } \\
\text { Island, Italy (Galderisi et al. 2012). }\end{array}$ & $\begin{array}{l}\text { Identifies which attributes } \\
\text { influence vulnerability and/or } \\
\text { resilience, providing a basis } \\
\text { for further research. } \\
\text { Provides relative spatial } \\
\text { distribution of areas of } \\
\text { different vulnerability. }\end{array}$ & $\begin{array}{l}\text { Assigning qualitative } \\
\text { descriptions or numerical values } \\
\text { to indicators is subjective. } \\
\text { Difficult to have common } \\
\text { indicators and rankings for } \\
\text { different spatial scales and } \\
\text { different infrastructure designs. }\end{array}$ \\
\hline
\end{tabular}
(e.g., high, medium, low) or with numerical values that can be summed to provide an overall vulnerability value/score.

\section{Impact Impact state scales categorise states (IS) infrastructure damage or disruption into a set number of defined states, typically ranging from no damage to complete destruction. Each state is typically assigned a numerical vulnerability value such as repair cost, damage ratio (repair cost relative to replacement cost) or percentage of damage.}

Threshold Similar to damage states in that levels impacts are categorised into a set number of states; however, in addition to the vulnerability values, each impact state is also assigned hazard intensity threshold values (e.g., tephra thickness, dynamic pressure).

Fragility and Quantitative functions (i.e., vulnerability mathematical equations).

functions Vulnerability functions express relative loss or economic cost to hazard intensity.

Fragility functions express the probability of a level of impact being equalled or exceeded for a given hazard intensity.
Threshold level scales developed to indicate hazard intensity for each damage state for buildings and critical infrastructure (Spence et al. 2004; Jenkins et al. 2014b, Wilson et al. 2014).

Fragility functions developed for tephra fall impacts on buildings and electrical transmission systems (Spence et al. 2005; Zuccaro et al. 2008; Wardman et al. 2012b).
Damage scale for classification of following 1991 Mt. Pinatubo eruption (Spence et al. 1996).
Allows simple classification of impact into a number of states.

Highlights areas of relatively high/low vulnerability. Provides distribution of impact states and comparison between impacted areas.

Easy to process posteruption.

Provides a relationship between impact state (i.e., damage and disruption) and hazard intensity. Accounts for some uncertainty within vulnerability estimates through the range of hazard intensity threshold values provided.

Impact intensity relationship is provided as a changing probability estimate over a range of hazard intensities. Mathematical approach accounts for some of the uncertainty associated with these assessments. The functions can directly inform quantitative risk assessments for impact and loss estimation.
Qualitative impact descriptions do not cover all aspects of impact or infrastructure design.
Selected hazard intensity metrics may not be appropriate to estimate impacts for all infrastructure components. The wide range of infrastructure design and operation characteristics influences vulnerability.

Requires large statistically valid datasets for robust correlations. Selected hazard intensity metric may not be the most appropriate to estimate impact for all infrastructure components.

Functions are only applicable to the infrastructure typology they were derived for and may not be applicable elsewhere without modification.
2. Fragility functions quantify the probability that a particular impact state will be equaled or exceeded as a function of hazard intensity.

A benefit of fragility functions is that they can be plotted as suites of data so that the likely impact across assets with differing vulnerability is described in a visually appealing and easy-to-interpret form. For example, multiple buildings in an area with the same hazard intensity (e.g., $200 \mathrm{~mm}$ tephra thickness) may have different impact states (e.g. undamaged, damaged gutters, collapsed roof) because of variations in vulnerability. A set of fragility functions for tephra thickness describes the likely impacts across these buildings at $200 \mathrm{~mm}$ (and other tephra thicknesses). Whether vulnerability or fragility functions are derived is dependent on the specifications of the vulnerability assessment and available 
volcanic impact data. For volcanic risk assessment, the functions account for uncertainties (through probabilities) in the link between hazard intensity and damage (loss) upon which risk mitigation and management decisions are based. Functions can also be developed which consider mitigation actions, such as strengthening of components or clean-up, providing useful data for risk reduction costbenefit analyses. Fragility functions are commonly used for earthquake (e.g., Porter et al. 2007), tsunami (e.g., Reese et al. 2011; Mas et al. 2012), mass movement (e.g., Quan Luna et al. 2011; Totschnig et al. 2011) and flood (e.g., Reese and Ramsay 2010; De Risi et al. 2013) vulnerability and risk assessments.

\section{Existing volcanic vulnerability and fragility functions}

Volcanology has fewer existing vulnerability and fragility functions than some other natural hazard fields (e.g., earthquake). Reasons for this include: (1) limited data from which functions can be derived because the systematic collection and analysis of impact data for volcanic hazards is in its infancy (generally evolving post 1980 following the eruption of Mount St Helens); (2) infrastructure hazard assessments rarely account for volcanic hazards; (3) catastrophe modelling by (re)insurance organisations often does not consider volcanic hazards; (4) there are no building or infrastructure design codes for volcanic impacts which would prompt the derivation of functions; and (5) volcanic eruptions are often infrequent events on human and infrastructure timeframes (Douglas 2007; Wilson et al. 2014). In addition, a range of intrinsic volcanic hazard properties can cause different impacts, leading to difficulties in deriving functions, for instance finer grainsize tephra will generally more rapidly block air filters compared to the same volume per unit area of coarser tephra. Despite these challenges, several vulnerability and fragility functions have been developed for different volcanic hazards and critical infrastructure (e.g., Blong 2003a; Douglas 2007; Jenkins and Spence 2009; Jenkins et al. 2013, 2014a, 2014b, 2015; Kaye 2007; Maqsood et al. 2014; Pomonis et al. 1999; Schriever and Hansen 1964; Spence et al. 1996, 2004, 2005, 2007; Valentine 1998; Wardman et al. 2012a; Wardman et al. 2014; Wilson et al. 2012a; Wilson et al. 2012b; Zuccaro et al. 2008; Zuccaro and De Gregorio 2013).

Key findings emerge from critical infrastructure impact (Blong 1984; Wilson et al. 2012a; Wilson et al. 2014) and volcanic fragility function literature:

1. A number of vulnerability and fragility functions are available for buildings for tephra fall (Spence et al. 2005; Kaye 2007; Jenkins and Spence 2009; Maqsood et al. 2014), pyroclastic density currents (Spence et al. 2007; Zuccaro et al. 2008; Jenkins and Spence 2009) and lahar (Zuccaro and De Gregorio 2013; Jenkins et al. 2015) impacts.
2. There have been few (e.g., Kaye 2007; Wardman et al. 2012a; Wilson et al. 2012a) attempts at developing volcanic vulnerability and fragility functions for critical infrastructure sectors. This is primarily due to difficulties assessing vulnerability across a wide range of infrastructure types, designs, operating practices and societal pressures.

3. The majority of available volcanic vulnerability and fragility functions are derived for specific infrastructure and building typologies. While this increases their accuracy for local risk assessments, these functions are difficult to apply in other locations. Indeed, several authors have argued for the need to customise vulnerability and fragility functions to the study area to ensure accuracy (i.e. Jenkins et al. 2014a; Wilson et al. 2014).

Nevertheless there is an increasing requirement for regional or global volcanic risk and vulnerability assessments (e.g. the UNISDR Global Assessment of Risk; Jenkins et al. 2014b), thus derived functions need to account for a range of infrastructure typologies or assume generic typologies.

4. There are limited quantitative empirical (posteruption impact assessments and laboratory experiments), analytical or theoretical data to inform the development of volcanic fragility or vulnerability functions for critical infrastructure sectors.

5. A number of semi-quantitative impact state scales are available (e.g., Spence et al. 2004; Jenkins et al. 2014b; Wilson et al. 2014; Jenkins et al. 2015) from which vulnerability and fragility functions could be derived given sufficient impact data.

6. There is a reasonable amount of qualitative vulnerability data available, primarily from posteruption assessments, which can be used to inform quantitative volcanic vulnerability assessments.

What is currently missing is a methodology to combine qualitative and quantitative data to develop quantitative vulnerability estimates for critical infrastructure sectors. We address this gap here with a new volcanic vulnerability framework, which provides a method to use all available vulnerability data to derive vulnerability and fragility functions.

\section{Volcanic vulnerability and fragility framework}

To assess the vulnerability of critical infrastructure to volcanic hazards in a robust and systematic way, a framework is required to guide volcanic risk scientists in deriving vulnerability estimates. Our framework (Fig. 1) facilitates empirical derivation of volcanic vulnerability and fragility functions to quantitatively assess vulnerability of critical infrastructure to volcanic hazards, and is based upon similar frameworks used for earthquake (e.g., Rossetto et al. 


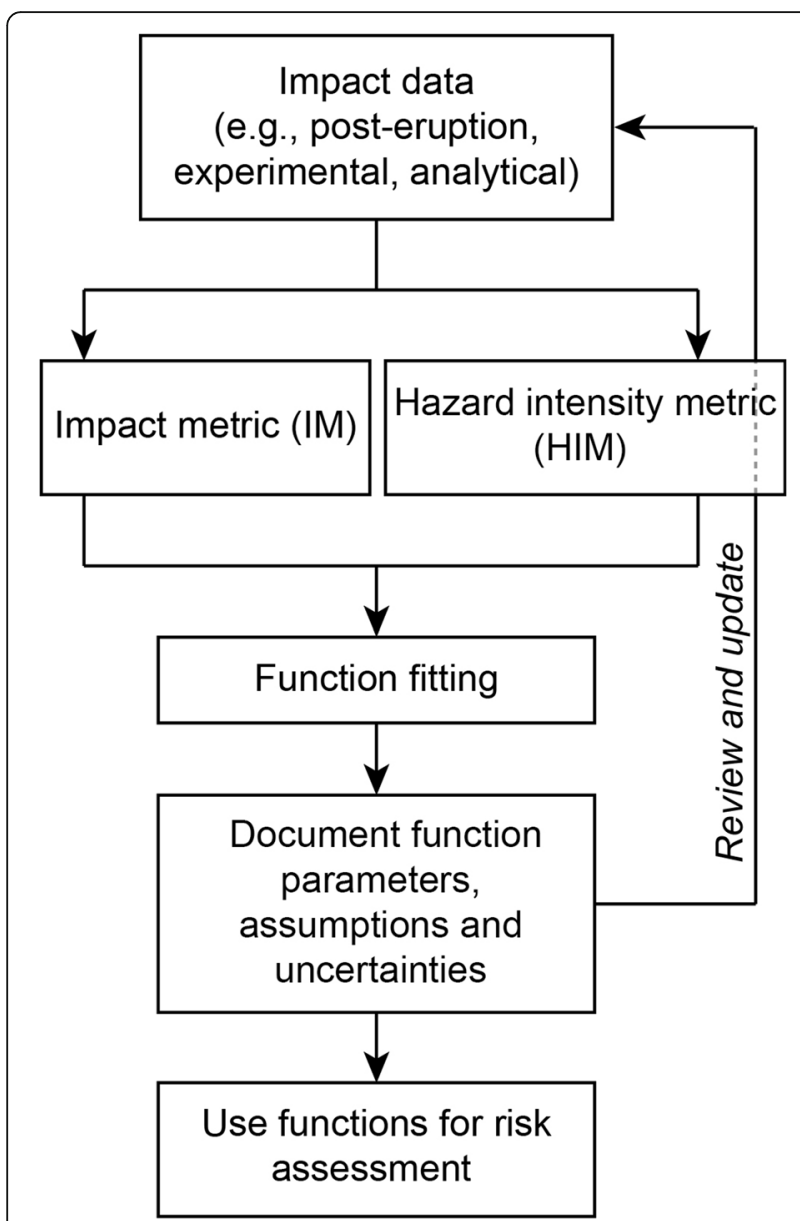

Fig. 1 Empirical framework for deriving volcanic vulnerability and fragility functions for critical infrastructure sectors

2014a) and tsunami (e.g., Tarbotton et al. 2015) vulnerability assessments.

\section{Impact data}

The data used to derive vulnerability and fragility functions is henceforth termed impact data. Impact data relates infrastructure impact to hazard intensity and can be classified into four main groups: empirical; expert judgment; analytical; and hybrid (Table 2).

A brief discussion of combining impact datasets (hybrid data) is warranted as this is the most likely approach for deriving volcanic fragility functions given the limited availability of impact data. Dataset are often combined to obtain sufficient data to derive fragility functions; care is required to do this appropriately as there will be different biases, sources and magnitudes of uncertainty amongst datasets (Calvi et al. 2006); this discrepancy can influence the quality of the resulting function(s).

In the case of post-eruption impact assessment data, there may be many different datasets available for numerous eruptions and locations, all of which could be of variable detail and quality. Rossetto et al. (2014b) suggests that prior to combining datasets, impact data should be harmonised by assuring that: (1) data type are of the same form, e.g., if one dataset is at building-bybuilding scale and another contains grouped data (e.g., multiple buildings in one area), the more detailed data should be aggregated to the grouped scale; (2) building and infrastructure typologies are consistent among datasets, if not, the most general typologies should be used; and (3) impact scales are identical across datasets, if not, a conversion to the coarsest scale (i.e., the scale with the least levels) should occur. Ensuring consistency among the different datasets permits more meaningful derivation of vulnerability and fragility functions. We recommend using standard infrastructure impact scales such as the recently developed Level 0-3 damage and disruption categories for tephra fall, PDCs, lava flows, and lahars (Wilson et al. 2014) for future post-eruption impact assessments and function derivation. However, we note that damage/impact states for other hazards such as earthquakes, cyclones/hurricanes and tsunami are often classified on alternative scales (e.g. Damage Level categories of 0-5), as are previous volcanic damage/impact states (e.g. Blong 2003c, Baxter et al. 2005). Therefore, additional analysis may be required to correlate previous work with Wilson et al.'s (2014) four-tier scale.

Due to differences in impact data quality we propose a qualitative quality rating system to indicate the quality of data for different infrastructure components and sectors (Table 3). To reduce uncertainties, high quality data should be preferentially used to derive volcanic vulnerability and fragility functions.

\section{Impact metrics (IM)}

An impact metric (IM) is used to assess the volcanic impact (e.g., damage) intensity for a particular infrastructure component or sector. IMs are commonly bounded between 0 and 1 or $0-100$ and are the dependent variable of vulnerability and fragility functions. For vulnerability functions, the IM can be a value or index which describes impact or economic loss. Any IM can be used for a vulnerability function depending on applicability and justification. Common IMs for vulnerability functions are:

\section{Damage percentage - percentage of damage} sustained by an asset compared to pre-impact condition (e.g., a building is $90 \%$ damaged after a lahar impact).

2. Loss of function - loss of function of an asset as a percentage compared to pre-impact condition (e.g., a water treatment plant lost $20 \%$ of its function after a tephra fall).

3. Damage index - damage percentage normalised between 0 and 1 . 
Table 2 Classification, advantages and disadvantages of volcanic impact data used to derive fragility and vulnerability functions. Modified from Schultz et al. (2010) and Wilson et al. (2014)

\begin{tabular}{|c|c|c|c|}
\hline Data classification & Data type & Advantages & Disadvantages \\
\hline Empirical & $\begin{array}{l}\text { Post-eruption } \\
\text { impact assessments } \\
\text { Laboratory } \\
\text { experiments }\end{array}$ & $\begin{array}{l}\text { Range of volcanic hazard and infrastructure } \\
\text { characteristics taken into account } \\
\text { Previous impacts are likely to occur again in the } \\
\text { future } \\
\text { Repeatable experiments in controlled } \\
\text { conditions }\end{array}$ & $\begin{array}{l}\text { Data highly site, region, infrastructure specific } \\
\text { Scarce data of variable quality } \\
\text { Difficulties in replicating volcanic hazards in laboratory }\end{array}$ \\
\hline $\begin{array}{l}\text { Expert } \\
\text { judgement }\end{array}$ & Expert elicitation & $\begin{array}{l}\text { Consider a wide range of impacts, including } \\
\text { those not previously observed } \\
\text { Not limited by impact data or models } \\
\text { Can be used to refine and update existing } \\
\text { functions } \\
\text { Widely accepted elicitation methods available }\end{array}$ & $\begin{array}{l}\text { Quality depends on subjectivity and expertise, particularly } \\
\text { if experience consists of atypical eruption impacts } \\
\text { Can be difficult to validate } \\
\text { Differing and contradictory opinions }\end{array}$ \\
\hline Analytical & $\begin{array}{l}\text { Numerical } \\
\text { modelling }\end{array}$ & $\begin{array}{l}\text { Increased reliability and repeatability and } \\
\text { reduced bias } \\
\text { Models can be validated against post-eruption } \\
\text { impact data } \\
\text { Can be extrapolated to new situations }\end{array}$ & $\begin{array}{l}\text { Substantial computation may be required for more } \\
\text { complex modelling } \\
\text { Models based on simplifications and assumptions }\end{array}$ \\
\hline Hybrid & $\begin{array}{l}\text { Combination of } \\
\text { different } \\
\text { approaches }\end{array}$ & $\begin{array}{l}\text { Can reduce limitations and uncertainties } \\
\text { through the combination of different data types }\end{array}$ & $\begin{array}{l}\text { Limitations are the same as individual approaches } \\
\text { Differences in data scale and aggregation (see text) }\end{array}$ \\
\hline
\end{tabular}

4. Function loss index - loss of function percentage normalised between 0 and 1 .

5. Damage ratio - a ratio between the cost of repair relative to the cost of replacement.

6. Economic cost - absolute cost of impact(s) in monetary value.

7. Impact state (IS) - states of damage and disruption defined by semi-quantitative impact descriptions (see the four level impact scale of Wilson et al. (2014)).
The IM for fragility functions is the probability of an asset equalling or exceeding a specified level of impact. Typically, the level of impact is defined by ISs with one function defined for each IS (i.e., a set of fragility functions) or only for the highest IS. As such, the fragility function gives the probability of equalling to or exceeding the $i^{\text {th }}$ IS. Given that ISs are sequential, such that IS implies that $\mathrm{IS}_{\mathrm{i}-1}$ has occurred, the probability of being equal to a specific IS can be calculated by the difference between consecutive ISs.

\section{Hazard intensity metrics (HIM)}

vulnerability data. We suggest that a precautionary approach should be taken where data could fall within two categories, assigning that data the lower quality rating option. For example, if a scientist witnesses an eruption but does not record the hazard intensity, then the 'D' quality rating should be assigned

\begin{tabular}{ll}
\hline Quality rating & Data quality description \\
\hline A (highest) & $\begin{array}{l}\text { Volcanic impacts documented following multiple }(>5) \\
\text { eruptions with large }(>50) \text { data points, and statistically } \\
\text { valid analytical modelling or experiments undertaken at } \\
\text { multiple recorded hazard intensities. }\end{array}$ \\
& $\begin{array}{l}\text { Volcanic impacts observed post-eruption with recorded } \\
\text { Bazard intensity, and experimental studies or analytical } \\
\text { calculations undertaken. }\end{array}$ \\
C & $\begin{array}{l}\text { Volcanic impacts witnessed by expert observers (e.g. } \\
\text { scientists, infrastructure operators) post-eruption, and } \\
\text { hazard intensity recorded. }\end{array}$ \\
D & $\begin{array}{l}\text { Volcanic impacts witnessed and/or reported post- } \\
\text { eruption by lay observers (e.g. public, media)), and haz- } \\
\text { ard intensity not recorded. }\end{array}$ \\
E (lowest) & $\begin{array}{l}\text { Volcanic impacts are possible, but not observed or } \\
\text { identified. }\end{array}$ \\
\hline
\end{tabular}

A hazard intensity metric (HIM) describes the intensity of a volcanic hazard at a particular site. It is the independent variable of vulnerability and fragility functions. Volcanic hazards have a number of different properties which can convey intensity, as not all HIMs adequately capture all of the impactful attributes of volcanic hazards (Wilson et al. 2014). Therefore, the selection of an appropriate HIM is important. As discussed in Wilson et al. (2014), the selection of a HIM must consider: (1) the HIM's appropriateness to describe a range of infrastructure impact intensities; (2) the ease of HIM measurement in the field or laboratory; (3) the applicability of the HIM to hazard model outputs; and (4) which HIM has been used in existing impact datasets. The most common HIMs are (Wilson et al. 2014): thickness or mass loading (tephra fall, PDC deposits, lahar deposits), dynamic pressure (PDC, lahar), flow height (lava flow, lahar), presence or absence (lava flow, gas emissions), density per unit area (ballistics), impact energy (ballistics) and concentration (gas emissions, tephra fall). 


\section{Function derivation}

Volcanic vulnerability and fragility function derivation requires: (1) data curation to convert raw impact data into a form which can be used for function derivation; and (2) a method to fit functions to available data.

\section{Data preparation}

Data preparation is generally required to derive volcanic vulnerability and fragility functions. For vulnerability functions, each data point needs to have a hazard intensity metric (HIM) value and an intensity metric (IM) value. For fragility functions, each data point needs to have a HIM value and an impact state (IS) level (a specific type of IM; Table 4). For the latter, data are ordered by increasing HIM value and binned, such that each bin has approximately the same number of data. The probability of equalling to or exceeding each IS can be calculated for each HIM bin. This is achieved by summing the number of data points which are greater than or equal to the IS of interest relative to the number of data points that are assigned to lower IS's (Fig. 2 for an example). Discrete HIM values are obtained by taking the median of each HIM bin. This method is commonly used to derive fragility functions for earthquake (Porter et al. 2007) and tsunami (Tarbotton et al. 2015) hazards. Despite the sparsity of quantitative data for volcanic impacts, the approach to bin the HIM values was adopted to produce a framework that is consistent with those used for other hazards. Additionally, by using this approach, initial fragility functions derived for volcanic hazards can be easily interpreted and modified as more data becomes available. The initial fragility function development will also highlight where particular impact data is lacking, identifying areas where analytical data, and empirical data collected through targetted laboratory experiments, can assist.

\section{Function fitting}

Any number of discrete or continuous mathematical functions can be fitted to impact data to obtain volcanic vulnerability and fragility functions. While in the earthquake community there are guidelines for best-practice function form (Rossetto et al. 2014b), there is no equivalent in the volcano community. In volcanology, the good faith practice is that selected functions represent the data appropriately. In data-poor contexts, these often take on binary or piecewise linear forms.

The simplest approach is using a binary function, such that below some hazard intensity threshold impact does not occur and above the threshold, impact occurs. For example, if lava is present, an asset (e.g., a road) may be considered completely destroyed whereas if lava is absent, the asset is undamaged.
Volcanic vulnerability and fragility functions can be described by linear equations applied to either the whole dataset or to individual segments; this is our preferred method for limited datasets. The start and end point of each line segment is defined by the available data points after the HIM binning process. In our function derivation examples below, we took this approach because only three HIM bins could be reasonably applied to the limited volcanic impact data; using a complex mathematical equation to interpolate between three data points was unjustified. Eq. 1 shows the form of the piecewise linear equation used to calculate the probability of the $I S$ equalling or exceeding the $i^{t h}$ IS:

$$
P\left(I S \geq I S_{i}\right)=\left\{\begin{array}{cc}
0 & H I M=0 \\
m_{1, i} H I M+c_{1, i} & k_{1}<H I M \leq k_{2} \\
m_{2, i} H I M+c_{2, i} & k_{2}<H I M \leq k_{3} \\
m_{3, i} H I M+c_{3, i} & k_{3}>H I M
\end{array}\right.
$$

where $m_{1, i}, m_{2, i}$ and $m_{3, i}$ are slope constants and $c_{1, i}, c_{2, i}$ and $c_{3, i}$ are intercept constants for three linear segments for the $i$-th IS. Constants $k_{1}, k_{2}$ and $k_{3}$, where $k_{1} \neq k_{2} \neq k_{3}$, are critical HIM values for which the different linear segments apply. Other mathematical equations, such as exponential and polynomial, can be used to define vulnerability and fragility functions; however, care must be taken with these and with linear equations, as they are unbounded on the $x$-axis and $y$-axis and could result in negative values or probabilities $>1$.

A note on normal and lognormal cumulative distribution functions (CDFs), commonly used in earthquake and tsunami fields to define infrastructure fragility functions (Rossetto et al. 2013; Tarbotton et al. 2015), is warranted. Porter et al. (2007) and Rossetto et al. (2013) note desirable properties of lognormal CDFs for fragility function derivation are that: (1) the function is constrained on the $y$-axis between 0 and 1 , which is ideal for fitting probabilities bounded in this range; (2) the $x$ axis is constrained between 0 and $+\infty$, which prevents negative hazard intensities; and (3) lognormal CDFs are skewed to the left which better represents earthquake damage data clustered around low hazard intensities. In volcanology, lognormal CDFs have been used for fragility functions for building damage as a result of tephra fall and ballistics (e.g., Spence et al. 2005; Jenkins and Spence 2009; Jenkins et al. 2014a; Blong et al. 2017) based on how well it represents building impact data and its use for earthquake hazards.

Mathematical equations can be fit to vulnerability and fragility data using statistical data fitting techniques, such as least squares or maximum likelihood estimation; see Baker (2014), Rossetto et al. (2014b), Lallemant et al. 
Table 4 Impact states for expected impacts to critical infrastructure as a function of tephra fall thickness. Modified and updated from Wilson et al. (2014)

\begin{tabular}{|c|c|c|c|c|c|}
\hline & $\begin{array}{l}\text { Impact } \\
\text { State }\end{array}$ & $1 S_{0}$ & $\mathrm{IS}_{1}$ & $1 S_{2}$ & $1 S_{3}$ \\
\hline & Description & No damage & Cleaning required & Repair required & $\begin{array}{l}\text { Replacement or financially } \\
\text { expensive repair }\end{array}$ \\
\hline \multirow[t]{3}{*}{ Electrical supply } & $\begin{array}{l}\text { Threshold } \\
(\mathrm{mm})\end{array}$ & $<3$ & $3-10$ & $10-100$ & $>100$ \\
\hline & Damage & No damage & $\begin{array}{l}\text { Possible abrasion to some } \\
\text { moving parts, infiltration of } \\
\text { tephra into substation } \\
\text { gravel. }\end{array}$ & $\begin{array}{l}\text { Damage to exposed equipment } \\
\text { especially those with moving parts, } \\
\text { possible electrical line breakage. }\end{array}$ & $\begin{array}{l}\text { Structural damage to some } \\
\text { equipment at generation and } \\
\text { transmission/distribution sites, } \\
\text { irreparable damage to moving } \\
\text { parts (e.g., hydro power turbines). }\end{array}$ \\
\hline & Disruption & No disruption & $\begin{array}{r}\text { Temporary disruption to se } \\
\text { cleani }\end{array}$ & $\begin{array}{l}\text { rvice caused by insulator flashover, } \\
\text { ng and repair. }\end{array}$ & $\begin{array}{l}\text { Widespread disruption to electrical } \\
\text { supply with possible permanent } \\
\text { disruption. }\end{array}$ \\
\hline \multirow[t]{3}{*}{$\begin{array}{l}\text { Water supply } \\
\text { network }\end{array}$} & $\begin{array}{l}\text { Threshold } \\
(\mathrm{mm})\end{array}$ & $<1$ & $1-20$ & 20-100 & $>100$ \\
\hline & Damage & No damage & $\begin{array}{l}\text { Possible clogging of filters } \\
\text { and some abrasion to } \\
\text { moving components. }\end{array}$ & $\begin{array}{l}\text { Damage to pumping equipment, } \\
\text { other moving parts and infilling of } \\
\text { tanks. }\end{array}$ & $\begin{array}{l}\text { Collapse of reservoir roofs and } \\
\text { infilling of open reservoirs and } \\
\text { tanks. }\end{array}$ \\
\hline & Disruption & No disruption & $\begin{array}{l}\text { Normal operation with } \\
\text { increased frequency of } \\
\text { filter cleaning and } \\
\text { increased turbidity. }\end{array}$ & $\begin{array}{l}\text { Contamination of water and } \\
\text { increased treatment required. } \\
\text { Possible water use restrictions. }\end{array}$ & $\begin{array}{l}\text { Severe contamination of water } \\
\text { supply and exhaustion of supply } \\
\text { due to damage and/or increased } \\
\text { demand. }\end{array}$ \\
\hline \multirow[t]{3}{*}{$\begin{array}{l}\text { Wastewater } \\
\text { network }\end{array}$} & $\begin{array}{l}\text { Threshold } \\
(\mathrm{mm})\end{array}$ & $<3$ & $3-10$ & $10-50$ & $>50$ \\
\hline & Damage & No damage & $\begin{array}{l}\text { Possible minor abrasion to } \\
\text { pumps, clogging of filters } \\
\text { and possible interference } \\
\text { with chemical treatment } \\
\text { process. }\end{array}$ & $\begin{array}{l}\text { Large amounts of sedimentation in } \\
\text { network some causing blockages, } \\
\text { some damage to treatment plant } \\
\text { components and possible infilling } \\
\text { of open tanks. }\end{array}$ & $\begin{array}{l}\text { Widespread sedimentation } \\
\text { throughout entire network causing } \\
\text { some blockages, irreparable } \\
\text { damage to pumps and extensive } \\
\text { structural damage to treatment } \\
\text { plant components. }\end{array}$ \\
\hline & Disruption & No disruption & $\begin{array}{l}\text { Reduced capacity, } \\
\text { operation with increased } \\
\text { cleaning of filters. }\end{array}$ & $\begin{array}{l}\text { Temporary disruption to service to } \\
\text { unblock network and clean tanks } \\
\text { possibly resulting in discharge of } \\
\text { untreated sewage. }\end{array}$ & $\begin{array}{l}\text { Long term to possible permanent } \\
\text { disruption to service. Unable to } \\
\text { treat wastewater. }\end{array}$ \\
\hline \multirow[t]{3}{*}{ Airport } & $\begin{array}{l}\text { Threshold } \\
(\mathrm{mm})\end{array}$ & $<1$ & $1-30$ & $30-150$ & $>150$ \\
\hline & Damage & No damage & $\begin{array}{l}\text { Possible abrasion of } \\
\text { runway, apron markings } \\
\text { and paved surfaces as a } \\
\text { result of clean-up } \\
\text { operations. }\end{array}$ & $\begin{array}{l}\text { Moderate abrasion of paved } \\
\text { surfaces and landing lights. }\end{array}$ & Complete burial. \\
\hline & Disruption & Airport open & Airport closure, reduced visib & ility and traction. & Possible permanent closure. \\
\hline \multirow[t]{3}{*}{ Road } & $\begin{array}{l}\text { Threshold } \\
(\mathrm{mm})\end{array}$ & $<1$ & $1-100$ & $100-250$ & $>250$ \\
\hline & Damage & No damage & $\begin{array}{l}\text { Possible increased abrasion } \\
\text { of road markings and } \\
\text { paved surfaces. }\end{array}$ & $\begin{array}{l}\text { Weak bridges may experience } \\
\text { structural damage. }\end{array}$ & $\begin{array}{l}\text { Complete burial, structural damage } \\
\text { to some bridges. }\end{array}$ \\
\hline & Disruption & No disruption & $\begin{array}{l}\text { Reduced visibility, loss of } \\
\text { traction, covering of } \\
\text { markings and possible road } \\
\text { closure. }\end{array}$ & $\begin{array}{l}\text { Roads impassable for some } \\
\text { vehicles. }\end{array}$ & $\begin{array}{l}\text { Roads impassable if tephra is } \\
\text { unconsolidated, compacted tephra } \\
\text { may be driven on by some } \\
\text { vehicles. Likely road closures. }\end{array}$ \\
\hline \multirow[t]{3}{*}{ Rail } & $\begin{array}{l}\text { Threshold } \\
(\mathrm{mm})\end{array}$ & $<1$ & $1-30$ & $30-150$ & $>150$ \\
\hline & & No damage & \multicolumn{2}{|c|}{$\begin{array}{l}\text { Possible abrasion and/or corrosion of railway tracks and signals, } \\
\text { jamming of mechanical signals and contamination of track } \\
\text { ballast. }\end{array}$} & Complete burial \\
\hline & & No disruption & & Possible loss of grip and derailing. & Impassable. \\
\hline
\end{tabular}


Table 4 Impact states for expected impacts to critical infrastructure as a function of tephra fall thickness. Modified and updated from Wilson et al. (2014) (Continued)

\begin{tabular}{|c|c|c|c|c|c|}
\hline & & & $\begin{array}{l}\text { Reduced visibility, signals } \\
\text { and communications } \\
\text { disrupted. }\end{array}$ & & \\
\hline \multirow[t]{3}{*}{$\begin{array}{l}\text { Critical } \\
\text { components }\end{array}$} & $\begin{array}{l}\text { Threshold } \\
(\mathrm{mm})\end{array}$ & $<1$ & $1-10$ & $10-50$ & $>50$ \\
\hline & Damage & No damage & No damage & $\begin{array}{l}\text { Abrasion of moving parts and } \\
\text { blockage of filters. }\end{array}$ & $\begin{array}{l}\text { Extensive damage to most } \\
\text { components. }\end{array}$ \\
\hline & Disruption & No disruption & $\begin{array}{l}\text { Reduced function until } \\
\text { cleaned }\end{array}$ & $\begin{array}{l}\text { Reduced function and temporary } \\
\text { shutdowns until cleaned }\end{array}$ & $\begin{array}{l}\text { Uneconomic to repair, disruption to } \\
\text { service until replaced. }\end{array}$ \\
\hline
\end{tabular}

(2015), Tarbotton et al. (2015) and references therein for discussion and review of statistical data fitting techniques. Expert judgment can also be used to fit functions to limited or incomplete datasets or when simplifying complex problems, which is often required in volcanology. For expert judgment to be reproducible and transparent, we offer a list of guidelines for fitting functions to volcanic impact data using statistical data fitting techniques. These guidelines are not required when sufficient data are available to derive vulnerability estimates (e.g., earthquake vulnerability assessment), but are vital in volcanology where there are limited data to base vulnerability estimates on.

1. Individual functions in a set are sequential, such that $I S_{i+1}$ is never reached before $I S_{i}$. This allows the

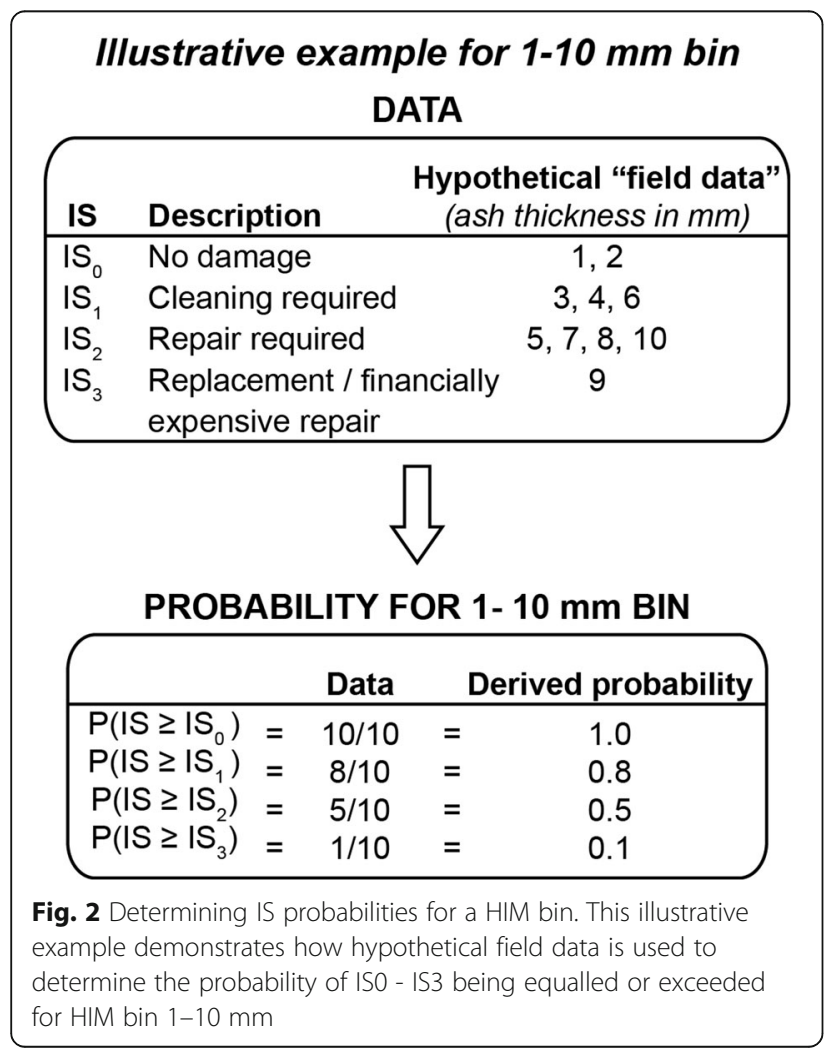

progressive accumulation of impact. For example, a building impacted by a PDC would not experience complete destruction and then experience damage to openings from missile impact. However, transitions along the IS sequence may be instantaneous and prior ISs may be omitted completely (e.g. during a lahar, a well-sealed building with few openings may not experience any infiltration of debris before complete damage).

2. Individual functions in a set can converge but not intersect. Intersecting functions violate the rule of sequential functions.

3. A probability of 0 means impacts will never occur and conversely a probability of 1 means impacts will certainly occur.

4. No impacts occur when the HIM value is zero. This rule assumes normal infrastructure operation in the absence of volcanic hazards.

5. Functions are non-decreasing, i.e., functions do not decrease as the HIM value increases. This rule assumes the impact intensity is constant or becomes more intense as volcanic hazard intensity increases.

6. Pre-condition (e.g., maintenance, age) of infrastructure sites can influence their vulnerability to volcanic hazards and functions should be modified for specific individual sites.

7. Factors such as equipment typology, level of preparedness, mitigation strategies can influence volcanic vulnerability and functions should be tailored to individual infrastructure sites on a caseby-case basis to address these site specific factors.

8. Different impact mechanisms can influence volcanic vulnerability and the interaction or dominance of different volcanic hazard impact mechanisms and should be considered.

\section{Uncertainty analysis}

There are a number of uncertainties which influence the quality of vulnerability and fragility functions (Table 5). Aleatoric (statistical) uncertainty is introduced by the natural variation of volcanic eruptions, hazard occurrence, or the variation of infrastructure response to volcanic hazards. 
Table 5 Sources of error and uncertainty for volcanic fragility and vulnerability functions

\begin{tabular}{ll}
\hline Factor & Source of uncertainty \\
\hline Hazard intensity & Lack of observed and/or measured HIM \\
metric (HIM) & Physical factors (e.g. compaction, erosion, natural \\
& local variations in hazard intensity) \\
& Incorrect measurement of HIM \\
& Incorrect or incomplete recording of HIM (e.g. \\
& units missing) \\
& Selection of appropriate HIM \\
& Localised variation in impact on assets \\
& Asset typology (e.g. condition, age, consturction \\
& quality) and difficulties in assigning post-event \\
& Uncertainty in the definition of ISs \\
& Incorrect classification of observed impacts into \\
& ISs \\
& Limited number of observations, spatial coverage \\
& and biased samples \\
& Sampling methodology \\
& Differences in asset vulnerability for the same \\
& asset typology \\
Incorrect identification of asset typology \\
Limited number of observations for each asset \\
typology \\
tyset data \\
$\begin{array}{l}\text { Data manipulation } \\
\text { Expert judgment biases } \\
\text { Selection of statistical model to represent } \\
\text { function }\end{array}$ \\
\hline
\end{tabular}

Different sources of epistemic (systematic) uncertainty are associated with HIMs and the volcanic impact dataset (Rossetto et al. 2014a). As single HIMs cannot adequately describe all the impactful aspects of a particular hazard, a compromise is made when selecting a HIM for vulnerability and fragility functions introducing uncertainty. This could be overcome by deriving multiple volcanic function sets for different HIMs or combining multiple HIMs. In addition, most volcanic HIMs cannot be measured in real time and rely on measurements taken after an event, eyewitness reports, and inference from volcanic deposits or impacts. For example, it is difficult to measure dynamic pressures of PDCs due to their potential to cause injury and destroy measurement equipment; therefore, the dynamic pressure is typically estimated from deposits or resulting asset damage (e.g., Jenkins et al. 2013). This can lead to large uncertainties in the measurement of volcanic hazard intensity (e.g., Engwell et al. 2013).

Large sources of uncertainty within volcanic impact data arise from the classification of impacts into ISs and the often small sample size. The number of observations in volcanic impact datasets can affect data interpretation and statistical analysis. Currently this is a large source of uncertainty for volcanic hazard vulnerability and fragility functions, with many datasets containing few data $(\sim 10 \mathrm{~s}$ of data points). As a comparison, for earthquake fragility functions, Rossetto et al. (2014b) consider $\sim 30$ buildings for each building class as a minimum for function derivation, with best practice involving $>100$ buildings.
Regardless of the source of uncertainty or its magnitude, identification, minimisation and quantification of all uncertainties should be undertaken. Rossetto et al. (2014a) considers this a fundamental step in the derivation of vulnerability and fragility functions for infrastructure assets.

For the volcanic fragility functions derived in the following section Volcanic Tephra Fall Fragility Functions, uncertainty is accounted for at each HIM value by calculating the probability that an infrastructure site could be in one of four ISs. Variation in the HIM value is taken into account by binning these values and using the median bin value as discrete HIM values on each fragility plot. Other approaches, such as the use of confidence intervals (e.g., 5th and 95th percentiles), could be used to account for uncertainties, particularly with large data sets where these intervals can be statistically estimated.

\section{Documentation}

Documentation of volcanic vulnerability and fragility functions is critical for their reproducibility, reliability and implementation. Users must understand what the functions show, how they were derived, their limitations and applicability. Transparency and understanding can be achieved by documenting the aspects in Table 6 for each (or set of) vulnerability and fragility function(s) for volcanic hazards. Documentation also provides the basis for review and updating of functions when further volcanic impact data becomes available.

\section{Tephra fall fragility functions \\ Overview}

In this section we present fragility functions for discrete tephra fall impacts to the electricity supply, water supply, wastewater and transport networks using the methodology outlined in the first half of this paper; Additional file 1 provides equations for all functions derived here. Buildings are not included here as a number of studies (e.g., Spence et al. 2005; Zuccaro et al. 2008; Jenkins and Spence 2009; Maqsood et al. 2014) have already derived fragility functions for different building typologies. The approach is transferable to other assets such as people and agriculture where impact data exists for certain localities (e.g. taking account of cultural or climatic factors specific to that region and hence the vulnerability of the asset). We focus on tephra fall as it is the most common and widespread volcanic hazard (Wilson et al. 2012a) and there are more tephra fall impact data available with which to derive fragility functions. We use tephra thickness as the HIM as it is the most commonly recorded HIM. Our fragility functions describe the probability of equalling or exceeding one of four ISs defined by Wilson et al. (2014) as: $\mathrm{IS}_{0}$ - no damage; $\mathrm{IS}_{1}$ - cleaning required; $\mathrm{IS}_{2}$ - repair required; and $\mathrm{IS}_{3}$ - replacement or financially 
Table 6 Required documentation for volcanic vulnerability and fragility function(s)

\begin{tabular}{ll}
\hline $\begin{array}{l}\text { Required documentation } \\
\text { aspect }\end{array}$ & Description \\
\hline $\begin{array}{l}\text { Infrastructure sector and } \\
\text { sub-sector applicability }\end{array}$ & $\begin{array}{l}\text { The infrastructure sector and/or sub-sector } \\
\text { that the functions have been derived for } \\
\text { and which sector they are applicable to } \\
\text { (e.g., are functions derived for an entire } \\
\text { water supply sector or the underground } \\
\text { pipe network). }\end{array}$
\end{tabular}

Specific asset typology

The specific asset typology (e.g., a specific type of water pump) the functions have been derived for or an indication if functions are for mixed typologies (e.g., all water pump designs).

Data source(s)

Source (bibliographic reference if available) of the volcanic impact data used to derive functions. If expert judgment was used, a description of how the judgment process was conducted is recommended.

Data quality rating

Overall quality of the impact dataset used based on the quality rating scheme in Table 3.

Number of observations

The total number of observations (data points) used to derive fragility and vulnerability functions.

Impact metric (IM)

The impact metric used and justification for its use.

Hazard intensity metric (HIM)

The volcanic hazard intensity metric used and justification for its use.

Impact state (IS)

The volcanic impact state scale used or if a new scale was developed, a description of each impact state and justification for its use.

Function form, fitting and manipulation

The mathematical form of the functions used (e.g., linear, lognormal CDF, binary), the fitting technique used (e.g., linear regression, least-squares, expert judgment) and any data manipulation performed.

Assumptions

Discussion of any and all assumptions and decisions made during the process of data manipulation and function fitting.

Uncertainties

Discussion and identification of the uncertainties associated with the derived functions and how they are accounted for.

Limitations

Discussion of any and all limitations of the derived functions. In particular, limitations which indicate what the function should not be used for.

expensive repair (Table 4). Functions were fit using segmented linear equations and modified with expert judgment where functions violate data fitting rules (see section Function Fitting). Additional file 2 highlights vulnerable components and key knowledge gaps for each sector.

\section{Caveats}

The following caveats apply to all fragility functions here:
1. Presented fragility functions only consider generic infrastructure design and typology due to limited vulnerability data on specific typologies.

Vulnerability will be different when considering different typologies and sites; therefore, functions should be tailored on a site-by-site basis.

2. Interdependencies between infrastructure sectors are not considered; the vulnerability of each sector is assessed in isolation. Interdependencies between sectors are complex, often with multiple and bidirectional failure modes. For example, transportation may rely on continuous electricity for traffic signals, but the electricity network may rely on transportation for generator fuel supply (Rinaldi et al. 2001, Blake 2016). Interconnected systems create benefits during normal operation, but can bring vulnerabilities and challenges when natural hazards are encountered (Hughes and Healy 2014, Blake 2016) and will likely influence overall vulnerability.

3. Presented fragility functions only consider discrete tephra fall events and not prolonged, reoccurring or remobilised tephra falls, nor clean-up and restoration of infrastructure sectors following tephra fall.

4. Cumulative multi-hazard effects are not considered, and some assets may encounter multiple impacts with different intensities from various volcanic or other natural hazards.

5. Mitigation actions are not considered.

\section{Electricity supply network}

Electricity supply networks comprise electricity generation sites, substation sites and transmission networks. These three sub-sectors differ in the type of equipment used and resulting tephra impact mechanisms and are therefore considered separately. Commonly observed tephra fall induced impacts are: insulator flashover; breakage of transmission lines; abrasion of turbines and cooling systems at generation sites; and disruption of service at substations (Wardman et al. 2012a).

\section{Available tephra fall vulnerability data}

The majority of the vulnerability data for electrical networks impacted by tephra falls comes from posteruption impact assessments. There are data for at least 10 eruptions dating back to the $1980 \mathrm{Mt}$. St. Helens eruption; summarised by Wardman et al. (2012a) and Wilson et al. (2014). The majority of these data report impacts to transmission and distribution networks, although there are some data for generation and substation sites. The data are primarily qualitative and document disruption and damage as a function of tephra fall intensity. Wardman et al. (2014) conducted systematic laboratory experiments to determine the probability of insulator flashover as a function of tephra thickness 
and moisture content. Experiments to document flashover were conducted in a controlled environment using different insulator types common in New Zealand with both dry and wet tephra. Other experimental research on tephra induced insulator flashover was conducted by Nellis and Hendrix (1980) and Matsuoka et al. (1995). Laboratory experiments by Zorn and Walter (2016) examined changes in solar panel performance as a function of increasing tephra thickness; however, this study is limited in scope (i.e., only examined horizontal panels) and is not applied here. We assess and summarise the quality of the available vulnerability data for electrical generation sites, substations and transmission networks in Table 7 based on the scale presented in Table 3.

\section{Fragility functions}

Electricity generation Tephra can affect electricity generation through impacts to the cooling systems of thermal power stations and through abrasion of hydroelectric power (HEP) turbines. These impacts can cause disruption to electricity generation.

Due to the size and scale of equipment used at electricity generation sites, no experiments have been undertaken to systematically determine the vulnerability of these to tephra fall. Thus, the fragility functions presented here are based on post-eruption impact assessment data. Twelve case studies documenting impacts to different generation types are available; Fig. 3a shows that the majority are classified as $\mathrm{IS}_{1}$ (cleaning required) with no documented cases of $\mathrm{IS}_{3}$ (replacement or financially expensive repair).

Impact mechanisms for the three generation types (hydroelectric, thermal and geothermal) considered here are fundamentally different; however, there are insufficient data to derive separate fragility functions for each generation type. Therefore, all data are used, with expert judgment to avoid violating data fitting rules, to derive a set of fragility functions (Fig. 3b) for mixed-generation types (i.e., all hydroelectric, thermal, and geothermal generation). While no available case studies document impacts at $\mathrm{IS}_{3}$, we assume they are likely to occur in future eruptions and therefore $\mathrm{IS}_{3}$ has been included in the fragility function with a probability 0.2 for the 51$300 \mathrm{~mm}$ bin (based on expert judgement). See Wardman et al. (2012a) for a full treatment of tephra fall impacts to power stations.

Substations Substations are vulnerable to tephra fall primarily due to flashover on insulators and energised components, ash contamination causing reduced resistivity of gravel ballast in substation yards (and thus increasing step-touch potential), and blockage of transformer cooling systems (Wardman et al. 2012a).
Table 7 Quality rating of available tephra fall impact data for considered sectors

\begin{tabular}{|c|c|c|c|}
\hline Sector & Sub-sector & Assets & $\begin{array}{l}\text { Quality rating } \\
\text { (see Table 3) }\end{array}$ \\
\hline \multirow[t]{10}{*}{ Electricity } & \multirow[t]{3}{*}{$\begin{array}{l}\text { Generation } \\
\text { sites }\end{array}$} & $\begin{array}{l}\text { Hydroelectric power } \\
\text { (HEP) }\end{array}$ & C \\
\hline & & Thermal power & $\mathrm{D}$ \\
\hline & & Geothermal power & $\mathrm{D}$ \\
\hline & \multirow[t]{5}{*}{ Substations } & Whole site & C \\
\hline & & Insulators & B \\
\hline & & $\begin{array}{l}\text { Transformers/switch } \\
\text { gear }\end{array}$ & C \\
\hline & & Control systems & C \\
\hline & & Gravel ground cover & C \\
\hline & \multirow[t]{2}{*}{ Transmission } & Insulators & B \\
\hline & & Conductors (lines) & C \\
\hline \multirow[t]{5}{*}{ Water supply } & Water source & General & C \\
\hline & \multirow[t]{2}{*}{ Pipe network } & Pipes & $\mathrm{D}$ \\
\hline & & Pumps & C \\
\hline & \multirow{2}{*}{$\begin{array}{l}\text { Treatment } \\
\text { plant }\end{array}$} & Whole site & C \\
\hline & & Water quality & B \\
\hline \multirow[t]{3}{*}{ Wastewater } & \multirow[t]{2}{*}{ Pipe network } & Pipes & $\mathrm{D}$ \\
\hline & & Pumps & C \\
\hline & Treatment & Whole site & C \\
\hline \multirow[t]{6}{*}{ Transportation } & \multirow[t]{2}{*}{ Road } & Road & B \\
\hline & & Vehicle & C \\
\hline & \multirow[t]{2}{*}{ Rail } & Track & $\mathrm{D}$ \\
\hline & & Train & $\mathrm{D}$ \\
\hline & \multirow[t]{2}{*}{ Aviation } & Airport & C \\
\hline & & Aircraft (in flight) & $B$ \\
\hline
\end{tabular}

There are 16 post-eruption impact assessments available. We are unaware of any experimental data for substation components. The majority of the post-eruption impact data are classified as $\mathrm{IS}_{1}$ (cleaning required; Fig. 4a) as a result of operators cleaning gravel ground cover or sensitive equipment such as transformers. Few instances of substation impact $\geq \mathrm{IS}_{2}$ have been documented due to precautionary shut-downs for cleaning (Fig. 4a). However, like generation sites, $\mathrm{IS}_{3}$ is likely to occur in future eruptions and is therefore estimated with a probability 0.2 for the $51-300 \mathrm{~mm}$ bin (Fig. $4 \mathrm{~b}$ ), again based on expert judgement at this stage.

Electricity transmission lines Electricity transmission lines are vulnerable to tephra fall resulting in temporary or permanent disruption of electricity supply. The majority of the 24 post-eruption impact data points are classified as requiring cleaning $\left(\mathrm{IS}_{1}\right)$ to be reinstated 

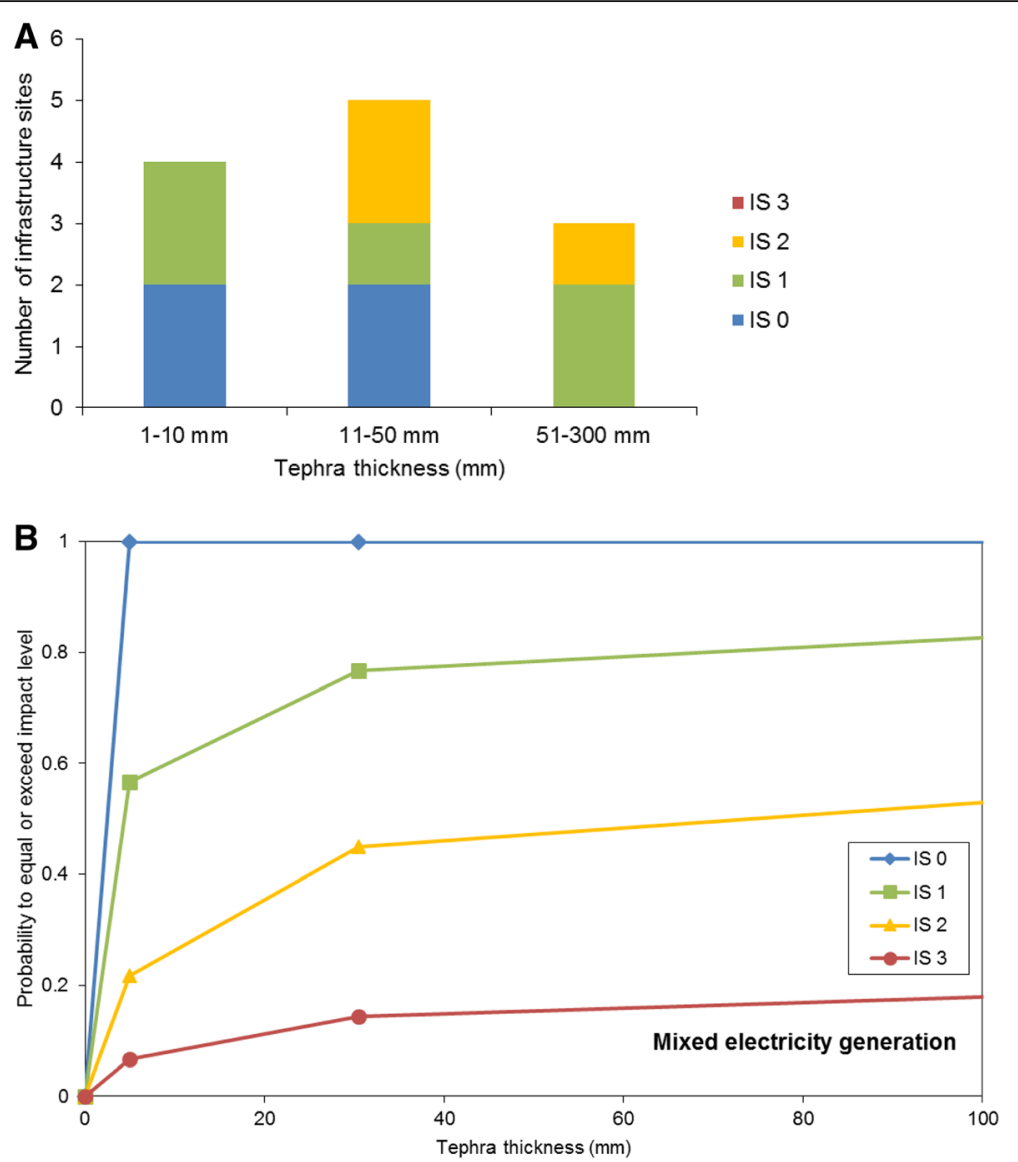

Fig. 3 Mixed electricity generation types (hydroelectric, geothermal and thermal) ash impact histogram and fragility functions. a Histogram of available post-eruption impact data classified by IS for 1-10, 11-50, and 51-300 mm tephra thickness bins. b Derived fragility functions for mixed electricity generation types showing probability of equalling or exceeding each IS vs tephra thickness

(Fig. 5a). Disruption is typically caused by flashover (the most common impact observed; Wardman et al. 2012a), controlled shutdowns to prevent damage, and cleaning of equipment. Physical damage such as line breakage $\left(\mathrm{IS}_{2}\right)$ has been documented in three previous eruptions (Wardman et al. 2012a). More intense damage $\left(\mathrm{IS}_{3}\right)$ has not been documented, although could reasonably occur in future eruptions. In addition to these post-eruption impact data, Wardman et al. (2012a) and Wardman et al. (2014) conducted laboratory experiments to investigate what volume and characteristics of tephra led to flashover on high voltage (HV) insulators. Insulator flashover is classified as $\mathrm{IS}_{1}$, and therefore, we used the Wardman et al. (2012a) flashover fragility function to inform and modify the $\mathrm{IS}_{1}$ function (Fig. 5b). The set of functions in Fig. $5 \mathrm{~b}$ are derived from all known impacts to transmission lines and estimate the probability of each ISs as a function of tephra thickness. We note that the functions do not specifically account for tephra moisture at this stage, however it should be noted that flashover probability is increased when tephra is wet (Wardman et al. 2012a).

\section{Water supply networks}

Water supply networks include water source areas (rivers, lakes, and groundwater), water treatment, storage facilities and distribution networks (above or below ground). Impacts commonly caused by tephra fall are: changes in water quality (chemical and turbidity); increased water demand (typically for tephra clean-up); abrasion of pumps; and blockage of filters at treatment plants. See Stewart et al. (2010) and Wilson et al. (2014) for further discussion of impacts to water supply networks.

\section{Available tephra fall vulnerability data}

The majority of the available vulnerability data for water supply networks comes from 14 post-eruption impact assessments from 1980 (Mt. St. Helens) to the present, summarised in Johnston et al. (2004), Stewart et al. (2010), Wilson et al. (2012a) and Wilson et al. (2014). These assessments are of variable quality and detail; they are predominantly qualitative data sets describing both disruption and physical damage. Studies by Hindin (1981), Stewart et al. (2006) and White et al. (2011) have quantitatively assessed impacts to water quality (chemical contamination and 

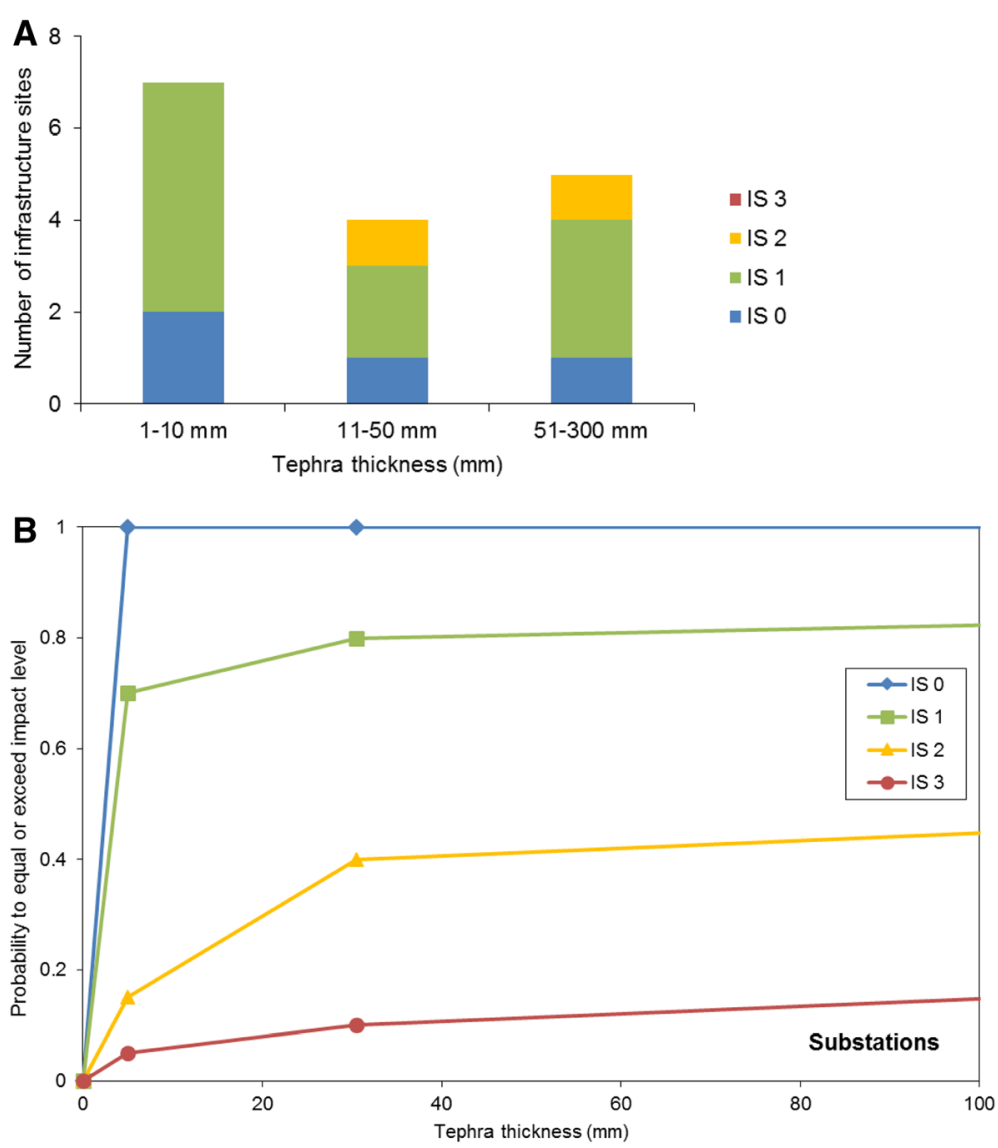

Fig. 4 Electricity substation ash impact histogram and fragility functions. a Histogram of available post-eruption impact data classified by IS for 1-10, 11-50, and 51-300 mm tephra thickness bins. b Derived fragility functions for electricity substations showing probability of equalling or exceeding each IS vs tephra thickness

turbidity) through numerical modelling and laboratory experiments. We are unaware of any quantitative studies on the physical impacts of tephra fall to water treatment plants (WTP) and pipe distribution networks. We assess and summarise the quality of the available vulnerability data for water supply sources, pipe networks and treatment plants in Table 7 based on the scale presented in Table 3.

\section{Fragility functions}

Tephra fall can impact water supply networks causing both disruption and physical damage. Analysis of posteruption impact data shows that the most common impact intensity is $\mathrm{IS}_{2}$ followed by $\mathrm{IS}_{1}$ (Fig. 6a). There is one instance of $\mathrm{IS}_{3}$ from Pacaya where above-ground pipes suffered damage from large tephra particles (Wardman et al. 2012b). Because there is only one instance of pipe damage, the set of fragility functions we derive here are for individual WTPs and not pipe networks. Water supply pipe networks are likely to be more resilient to tephra fall impacts as they are commonly underground and ingestion of tephra contaminated water is avoided; further research is required to confirm this. However, tephra deposited into water sources may be transported through the pipe network into the WTP, which could result in pipe damage. Tephra arriving at the WTP from the pipe network or from tephra contaminated subaerial reservoirs will likely increase system vulnerability.

The functions in Fig. $6 \mathrm{~b}$ reflect only direct tephra fall impact at a water treatment plant. Fig. 6b shows that for thin tephra falls there is a higher probability of tolerance $\left(\mathrm{IS}_{0}\right)$ and disruption type impacts $\left(\mathrm{IS}_{1}\right)$. As tephra thickness increases there is a higher probability of a water treatment plant being at $\mathrm{IS}_{2}$, reflecting the higher occurrence of these impacts during previous eruptions. While there are limited data to assess the probability of $\mathrm{IS}_{3}$, we assume that as tephra thickness increases, the probability of $\mathrm{IS}_{3}$ will also increase as a result of the increase likelihood of tephra induced abrasion of pumps. Abrasion damage on pumps and other mechanical components is more likely at tephra thicknesses $\geq 30 \mathrm{~mm}$ than $<30 \mathrm{~mm}$ (Wilson et al. 2014).

A limitation of this set of fragility functions is that the time required for abrasion damage and filter blockage to 

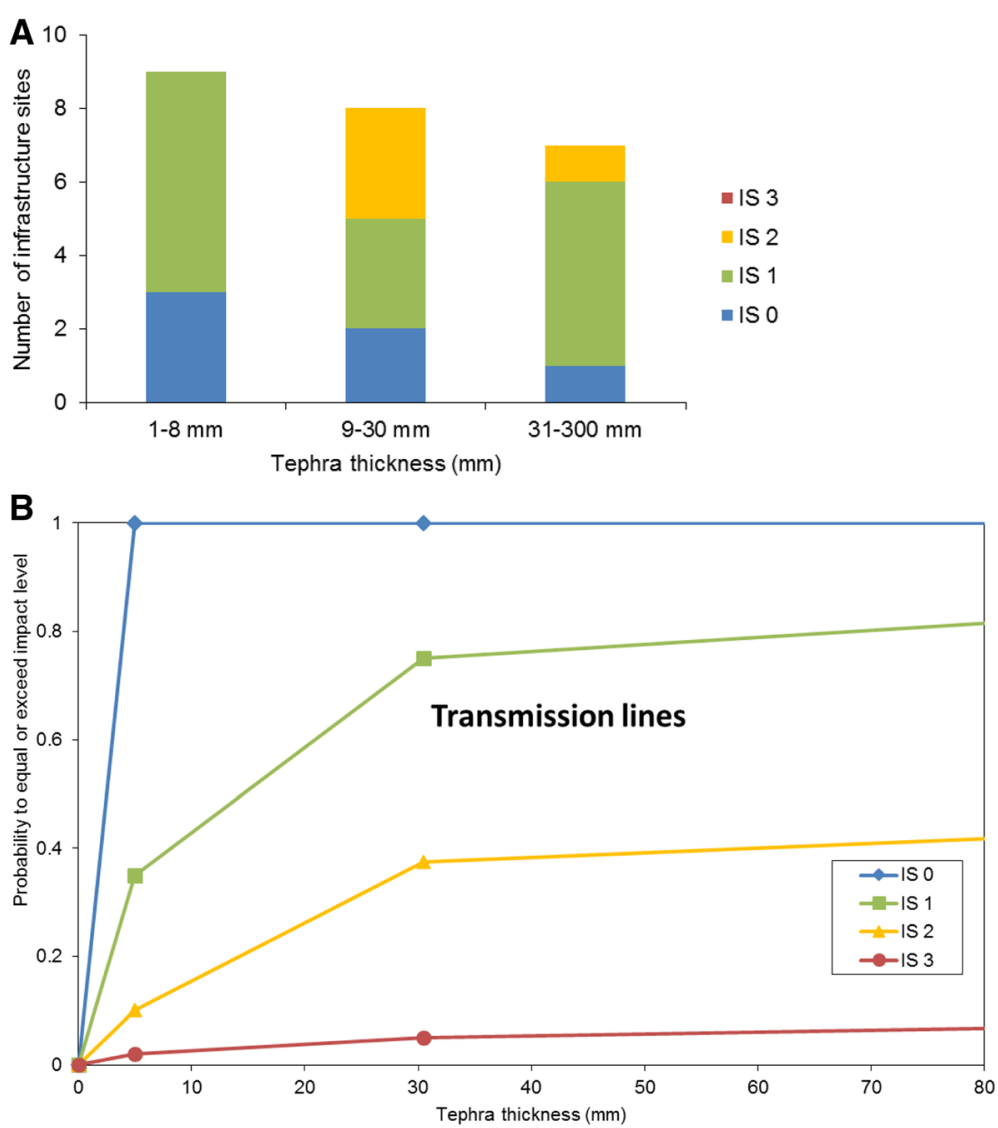

Fig. 5 Electricity transmission line ash impact histogram and fragility functions. a Histogram of available post-eruption impact data classified by IS for 1-10, 11-50, and 51-300 mm tephra thickness bins. b Derived fragility functions for electricity transmission lines showing probability of equalling or exceeding each IS vs tephra thickness

occur is not accounted for. These impact types are controlled by the tephra concentration (or 'dose') that components are exposed to over time, which is currently poorly understood and very sensitive to any mitigation measures applied. Therefore, discretion must be used when applying Fig. 6b functions as higher ISs $\left(\mathrm{IS}_{2}, \mathrm{IS}_{3}\right)$ are likely to occur sometime after a tephra fall event. In addition, WTPs can be highly specialised and specifically designed for the local/regional water characteristics. Each of the 20 post-eruption instances of water supply impact occurred at a WTP with different designs and layouts, and the subtlety of these differences is lost in deriving these functions (Fig. 6b). Therefore, we recommend that fragility functions for WTP be derived specifically for each water treatment site on a case-by-case basis to improve vulnerability assessments.

\section{Wastewater treatment network}

Wastewater networks comprise a network of underground collection pipes, pumps above-ground treatment facilities, and discharge pipes. Wastewater networks may be combined with stormwater systems or the two may be completely separate, with the former configuration increasing the overall network vulnerability as tephra can be ingested directly into the network (Barnard 2009). Impacts commonly caused by tephra fall are: abrasion of pumps and mechanical components; pipe blockages; and treatment disruption (collapse of biological processes) which could result in the bypassing of untreated wastewater. See Wilson et al. (2014) for further discussion of impacts to wastewater networks.

\section{Available tephra fall vulnerability data}

The two primary vulnerability data sets available for wastewater networks are post-eruption impact assessments and laboratory experiments. Impact assessments come from 8 eruptions between 1980 (Mt. St. Helens) and 2011 (Puyehue-Cordón Caullé) and are summarised by Barnard (2009) and Wilson et al. (2014). The only quantitative data we are aware of are the analogue laboratory experiments undertaken by Barnard (2009). Due to the size and cost of large wastewater treatment pumps, Barnard (2009) examined pump abrasion on smaller effluent pumps commonly used in agricultural 

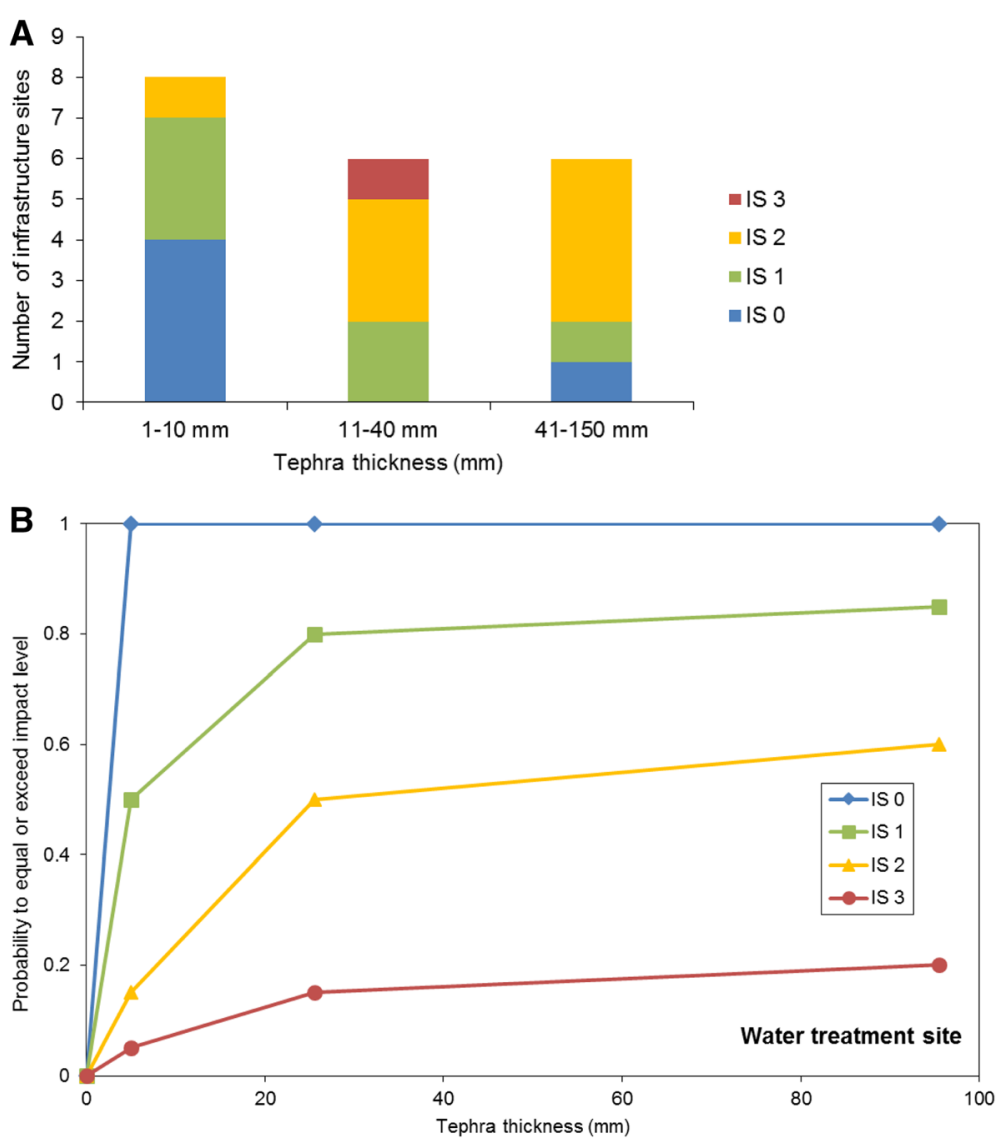

Fig. 6 Water supply treatment plant ash impact histogram and fragility functions. a Histogram of available post-eruption impact data classified by IS for 1-10, 11-40, and 41-150 mm tephra thickness bins. b Derived fragility functions for water supply treatment plant sites (excluding the influence of tephra deposited in water sources or transported through pipe networks) showing probability of equalling or exceeding each IS vs tephra thickness

settings. While these experiments cannot be directly compared to wastewater pumps, they can provide insight as to the potential impacts and guide any expert judgment. We assess and summarise the quality of the available vulnerability data for wastewater pipe networks and wastewater treatment plants (WWTP) in Table 7 based on the scale presented in Table 3.

\section{Fragility functions}

Available post-eruption impact data shows that the most common impact intensities are $\mathrm{IS}_{1}$ and $\mathrm{IS}_{2}$ (Fig. 7a). $\mathrm{IS}_{3}$ has been documented at tephra thicknesses between 5 and $25 \mathrm{~mm}$ after the $1980 \mathrm{Mt}$. St. Helens eruption. In this case the Yakima WWTP suffered severe abrasion damage to pumps and pumping components and the treatment plant was bypassed which resulted in the discharge of untreated waste into the Yakima River (Blong 1984). While these impacts are documented as occurring with tephra thicknesses between 5 and $25 \mathrm{~mm}$ (given by isopach maps), significantly more tephra likely passed through the treatment plants as tephra was washed into the stormwater network (Blong 1984). Therefore, the probability of exceeding $\mathrm{IS}_{3}$ increases as tephra thickness increases (Fig. 7b). However, for thicknesses $>10 \mathrm{~mm}$, there is a higher probability of a site being at $\mathrm{IS}_{2}$. This trend is influenced by the post-eruption impact data which contain a number of older wastewater networks which are combined with stormwater networks. Tephra can enter stormwater networks though drainage systems, introducing additional tephra into the wastewater treatment plant, leading to increased impact at lower recorded tephra thicknesses. This limitation of the derived functions is difficult to overcome with available data which does not record volume of tephra entering a treatment facility. By obtaining additional data which combines tephra volume and exposure time, vulnerability assessments will improve; however, this data is difficult to obtain.

In modern wastewater systems the stormwater network is typically separated, making it a closed system: tephra is less likely to arrive at the treatment plant through the pipe network, increasing overall resilience. Tephra may still accumulate at the plant 

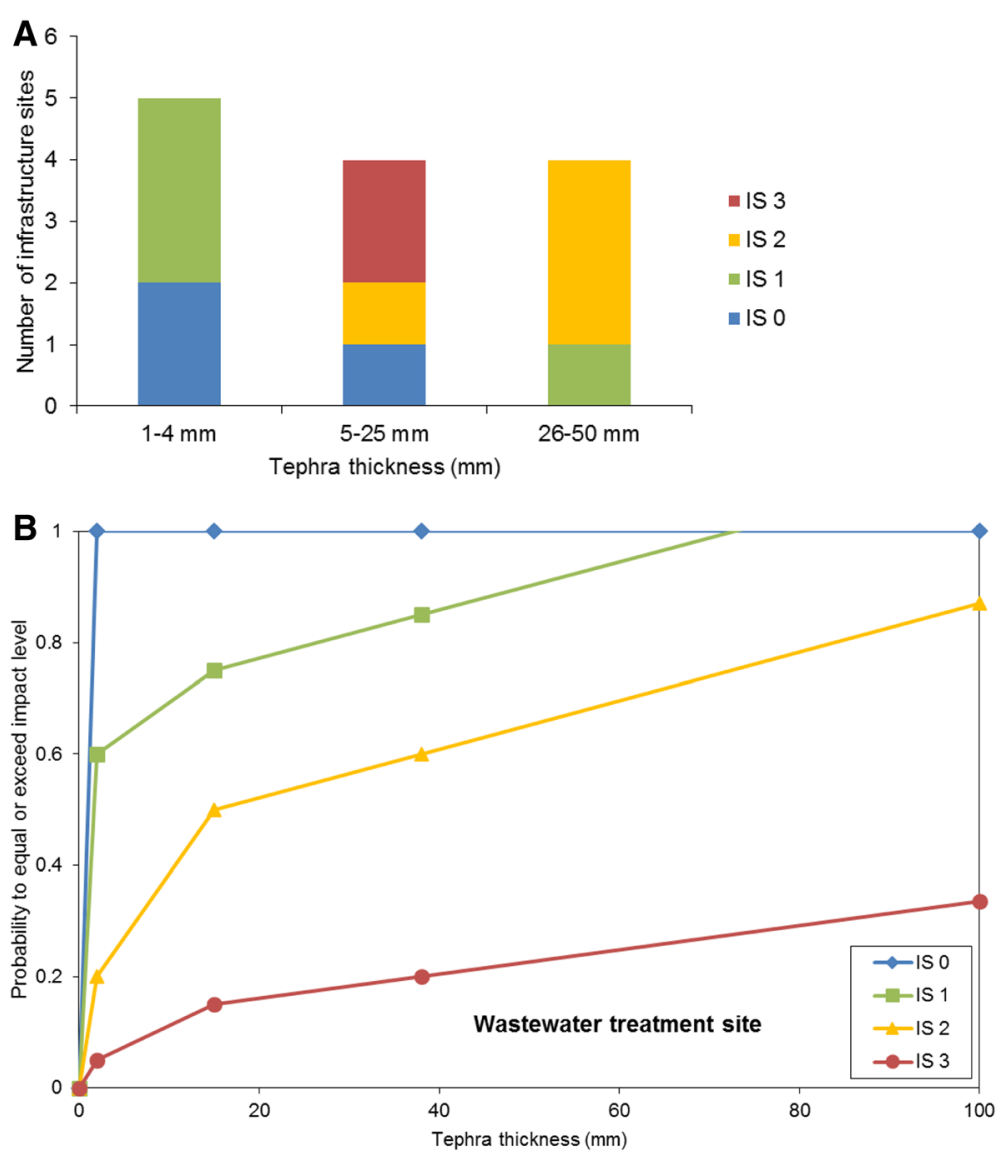

Fig. 7 Wastewater treatment plant ash impact histogram and fragility functions. a Histogram of available post-eruption impact data classified by IS for 1-4, 5-25, and 26-50 mm tephra thickness bins. b Derived fragility functions for wastewater treatment plant sites (excluding the influence of tephra entering and being transported through pipe networks) showing probability of equalling or exceeding each IS vs tephra thickness.

Values for tephra thickness $>50 \mathrm{~mm}$ are extrapolated

through direct air fall. As there is a limited understanding of how tephra enters and moves through wastewater pipe networks, the fragility functions in Fig. $7 \mathrm{~b}$ are derived only for individual treatment sites and do not consider the influence of tephra entering through the pipe network.

\section{Transportation networks}

Transportation networks include those on land, air and sea. Transportation networks typically include large expansive linear components (e.g., roads, railways), nodes (e.g., airports, ports) and vehicles (e.g., cars, trains). This section does not consider impacts to the marine sector, vehicles, trains, aircraft or support buildings (e.g., airport terminals and train stations). Impacts commonly caused by tephra fall include: reduction in visibility and traction; covering of roads and runways; and vehicle damage (windscreen and chassis abrasion, filter blockage, seized engines). See Wilson et al. (2014), Blake (2016) and Blake et al. (2016; 2017a, b) for further discussion of impacts to transportation.

\section{Available tephra fall vulnerability data}

The majority of the available transport vulnerability data are from post-eruption impact assessments and media reports and are typically qualitative. Large databases have been compiled documenting impacts to airports between 1944 and 2006 (Guffanti et al. 2008) and aircraft between 1953 and 2009 (Guffanti et al. 2010). A number of experiments have been undertaken to examine tephra impacts, particularly engine damage, to aircraft inflight (e.g., Drexler et al. 2011; Dunn 2012; Shinozaki et al. 2013; Davison and Rutke 2014; Song et al. 2014). Impacts to rail networks are relatively poorly documented, with the only available information from six eruptions. Recently, quantitative data which relates different road impact types to tephra intensity has been developed through experimental work. Barnard (2009) undertook a number of semi-quantitative field experiments to determine the difficulty of driving on roads covered by tephra of different thicknesses, primarily on the slopes of Mt. Etna, Italy. Blake et al. (2017a) conducted laboratory experiments to quantitatively examine 
the skid resistance (traction) and visibility of road markings on road surfaces covered by ash of different characteristics. Blake (2016) also conducted experiments quantifying visibility reduction during tephra falls. However, this paper does not incorporate results from these latest laboratory tests.

We assess and summarise the quality of the available vulnerability data for transportation networks in Table 7 based on the scale presented in Table 3.

\section{Fragility functions}

Road transportation Tephra fall can cause disruption to the road network and can lead to traffic accidents, congestion, reduced vehicle speed and possible road closure. Post-eruption impact data are used to derive road fragility functions. The reader is referred to Blake et al. (2017b) for illustration of how to incorporate targeted experimental results to refine fragility functions. The majority of the available post-eruption impact data can be classified as $\mathrm{IS}_{1}$ (Fig. 8a), suggesting that in most cases loss of traction and visibility will occur. Typically these impacts occur with thin $(\sim 1-3 \mathrm{~mm})$ tephra deposits (Table 4) and therefore, disruption of road transportation is common in distal areas. In a number of cases roads have been closed; however, this is typically determined by the risk tolerance and safety protocols of managing authorities. The set of fragility functions (Fig. $8 \mathrm{~b})$ reflect the tendency for more sites at $\mathrm{IS}_{1}$ across all tephra thicknesses, as it has the highest occurrence probability. At $100 \mathrm{~mm}$ there is a $\sim 0.2$ probability that a road remains in $\mathrm{IS}_{1}$ as post-eruption data and experiments by Barnard (2009) suggest that in some cases vehicles can drive through tephra deposits between 50 and $100 \mathrm{~mm}$ thick, albeit at a reduced speed. However, we note that the ground clearance of some vehicles is close to $100 \mathrm{~mm}$. The only available impact assessments for $\mathrm{IS}_{3}$ are from Barnard (2009) and Cole and Blumenthal (2004), who suggest that all vehicles become obstructed in $>300 \mathrm{~mm}$ tephra accumulation, and from Wilson (Chaitén 2008 eruption impact assessment field notes, unpublished), who identified that a non-engineered bridge sustained structural damage with $\sim 200 \mathrm{~mm}$ of tephra loading during the 2008 Chaitén eruption. We assume the probability of exceeding $\mathrm{IS}_{3}$ in the 101$1000 \mathrm{~mm}$ bin to be 0.1 based upon these assessments.

Rail transportation Railway lines can be disrupted during tephra fall as a result of tephra covering tracks, reducing grip, jamming mechanical switches and disrupting communication signals (Blong 1984; Magill et al. 2013). There have been six eruptions with documented impacts to railway lines due to tephra fall. Three eruptions are excluded from our fragility functions however; two
(Vesuvius 1906 and Sakurajima 1955-present) due to lack of reliable tephra intensity data, and one (Chaitén 2008) because of complications linked to thick snow accumulation at the time of ashfall. A total of eight observations are derived from the three remaining eruptions (Soufriere St Vincent 1902, Mt. St. Helens 1980 and Shinmoedake 2011). However, we highlight that each eruption affects a different rail type (i.e. tram, diesel or electric), and no distinction is made for our fragility functions although it is possible that tephra of the same intensity may result in a different impact state depending on the rail type. Further field or experimental data will confirm this in future.

Of the documented instances, the majority are at $\mathrm{IS}_{1}$ with an equal number at $\mathrm{IS}_{0}$ and $\mathrm{IS}_{2}$ (Fig. 9a). The set of fragility functions derived from these data and expert judgment show that $\mathrm{IS}_{1}$ has the highest probability of occurring for all tephra thicknesses (Fig. 9b). This reflects the documented tephra fall impacts which are primarily loss of function and minor damage. Most railway tracks are between $\sim 90-200 \mathrm{~mm}$ high (Mundrey 2010), so if tephra at least this thick accumulates, the track will be buried and train wheels will no longer make contact with the track, causing complete disruption. This is reflected in the fragility function with a probability of equaling or exceeding $\mathrm{IS}_{1}$ of 0.9 for the $11-40 \mathrm{~mm}$ bin, i.e., a low probability (0.1) of sustaining no impact (Fig. 9b). Tram tracks or tracks which are level with road surfaces (e.g., level crossings) are likely to be buried when thinner tephra deposits accumulate (i.e., they may become disrupted with lower tephra fall intensities).

Airports The most common impact to occur at airports during tephra fall is airport closure. Closure can result from tephra accumulating on runways and taxiways or the presence of tephra in the airspace surrounding an airport (not considered here). Blake et al. (2017a) investigates the skid resistance at airports, an important factor which enables aircraft acceleration, deceleration and change of direction on airfield surfaces. We are unaware of any instances of physical damage to runways or taxiways from direct tephra falls. However, at La Aurora International Airport, Guatemala, the runway was severely abraded after the 2010 eruption of Pacaya volcano as a result of tephra clean-up (Wardman et al. 2012b). Therefore, we only consider the probability that an airport will be closed (effectively $\mathrm{IS}_{1}$ ) during tephra fall. Also the probability of closure is likely more useful to airport operators before and during an eruption than an estimate of potential damage.

Guffanti et al. (2008) catalogued impacts, primarily caused by tephra fall, to airports between 1944 and 2006. From this database, 44 instances where tephra thickness and airport status (open or closed) was recorded (Fig. 10a) were extracted to calculate the probability of airport 

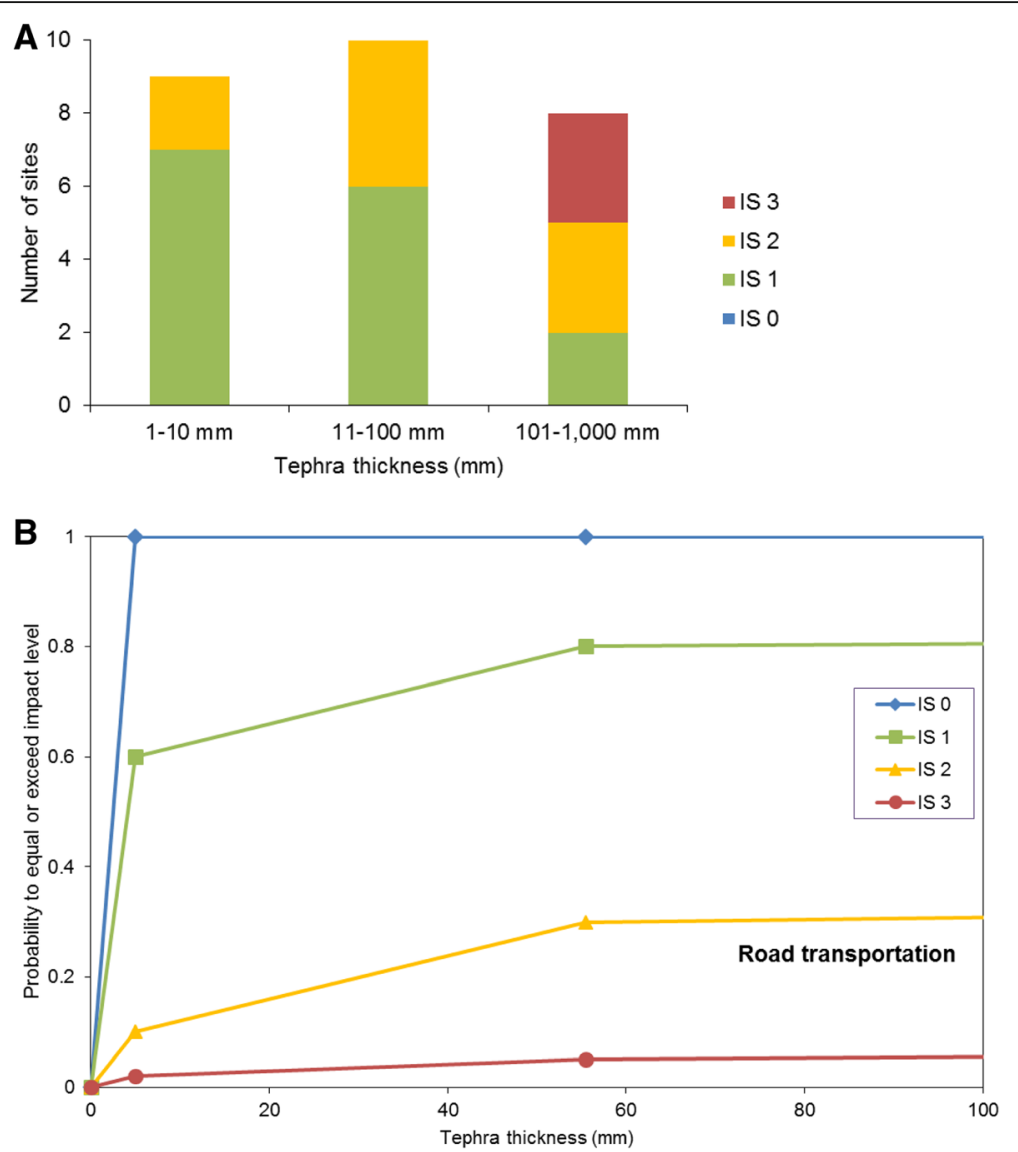

Fig. 8 Road transportation ash impact histogram and fragility functions. a Histogram of available post-eruption impact data classified by IS for 110,11-100, and 101-1000 mm tephra thickness bins. b Derived fragility functions for road transportation showing probability of equalling or exceeding each IS vs tephra thickness

closure as a function of tephra thickness (Fig. 10b). The resulting binary function shows that the probability of closure rapidly increases at low tephra fall intensities, up to 0.8 at $4 \mathrm{~mm}$, and at $20 \mathrm{~mm}$ all documented cases report airport closure. The main factors influencing airport closure are aircraft damage and life safety. Aircraft can sustain severe damage flying though tephra (Guffanti et al. 2010), therefore airports close (in most cases at relatively thin tephra deposits) to reduce the likelihood of damage and aircraft crashes. However, factors such as operational requirements, scheduling and economics, not accounted for here, may determine at which point an airport closes.

\section{Critical components}

Critical components such as heating, ventilation and air conditioning (HVAC) systems and small electronics (e.g., control systems, computers) are integral to most infrastructure sectors. Vulnerability data from post-eruption impact assessments and laboratory experiments (Gordon et al. 2005; Barnard 2009; Wilson et al. 2012b) confirm that these components are impacted by tephra fall. Common impacts are: abrasion of fans and motors; blockage of filters and ventilation holes; decreased usability of computers; and temporary shutdown of systems. See Wilson et al. (2014) for further discussion of impacts to critical components.

All documented impacts are measured against tephra thickness. However, tephra thickness is not the most appropriate HIM to use for these components, as the primary damaging mechanism is ingestion of tephra into the component, which is primarily driven by component design. As such, fragility functions for critical components are not derived here. Future experimental studies are required which consider the tephra concentration and the time components are exposed to tephra, i.e., experiments should match fragility to tephra 'dose'.

\section{Conclusions}

This paper presents a structured framework for the derivation of vulnerability and fragility functions for critical infrastructure. These functions provide quantitative estimates of impact intensity as a function of volcanic hazard intensity. Such functions are required for 

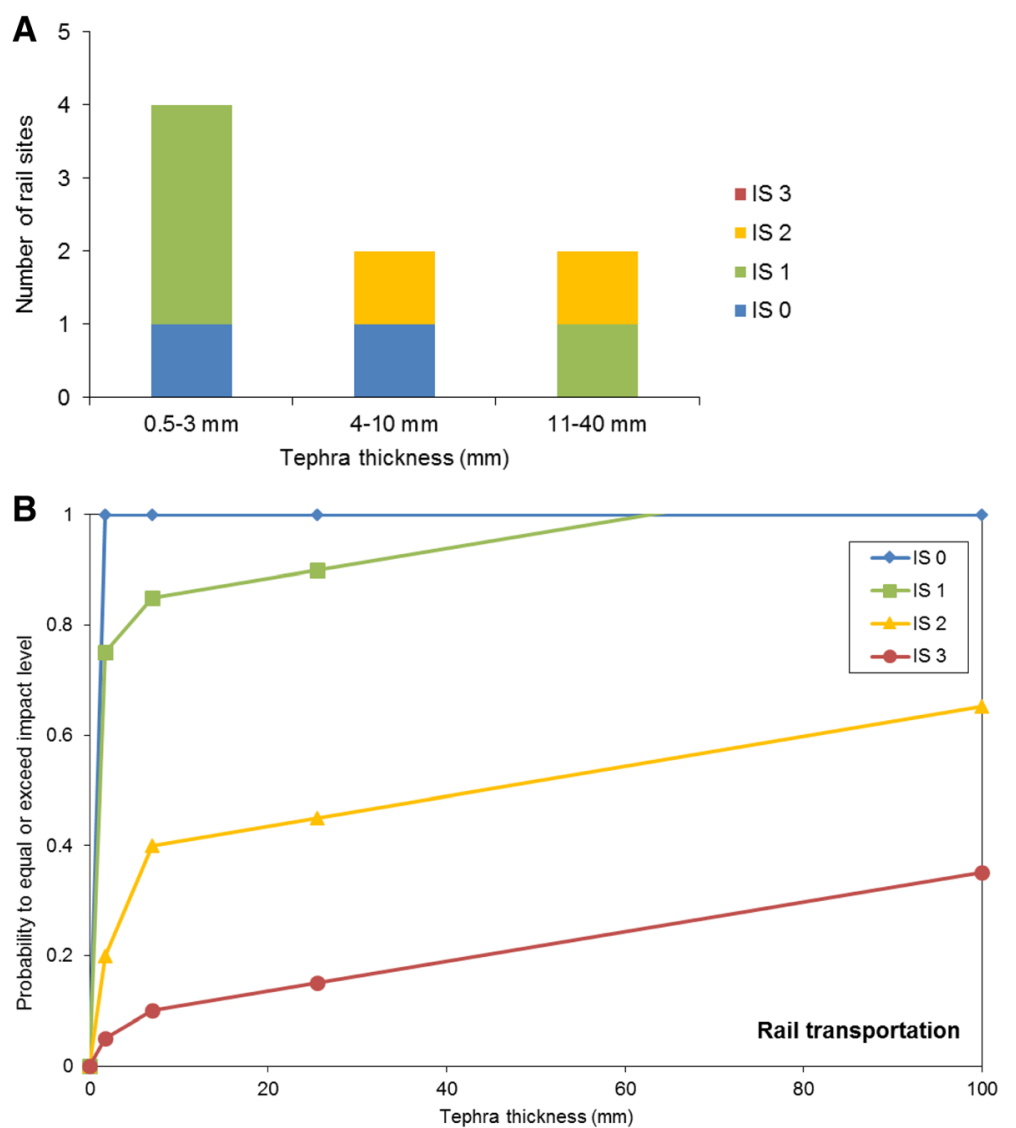

Fig. 9 Mixed rail transportation types (tram, electric, diesel) ash impact histogram and fragility functions. a Histogram of available post-eruption impact data classified by IS for $0.5-3,4-10$, and $11-40 \mathrm{~mm}$ tephra thickness bins. b Derived fragility functions for mixed rail transportation types showing probability of equalling or exceeding each IS vs tephra thickness. Values for tephra thickness $>50 \mathrm{~mm}$ are extrapolated

quantitative volcanic risk assessments. A standard framework promotes consistent vulnerability assessment and provides a method for the derivation of new fragility and vulnerability functions - a much needed step in volcanic risk assessment.

Our framework details data source and preparation, function requirements, data fitting approaches, uncertainty considerations and documentation required to derive a new vulnerability and/or function for a critical infrastructure sector or component impacted by volcanic hazards. The primary data source used here are posteruption impact assessments which document impacts from historic eruptions. Laboratory experiments are beneficial as they can be repeated to generate large impact datasets. Laboratory data are available for some infrastructure sectors and components but are limited due to the difficulties of replicating volcanic hazards and large infrastructure components interactions in the laboratory. Where data are limited, expert judgment complements independently obtained data in developing fragility and vulnerability functions. We provide a set of rules to guide expert data fitting to provide transparency in this part of this process. Using these rules, expert derived functions are based on a standard foundation and are mathematically valid. These rules are not required in cases where large datasets are available (e.g., earthquake vulnerability datasets) and therefore are a unique approach for fields with scarce vulnerability data, such as for volcanology.

Throughout the process of estimating fragilities and vulnerabilities, the quality of the resulting functions is affected by uncertainties related to raw data and its manipulation affects. Where possible, uncertainties should be minimised and documented. In addition, data preparation, the function derivation process and assumptions should be documented to ensure process transparency and repeatability. This also enables others to assess the quality and suitability of functions.

This paper demonstrates how our framework can be applied with the derivation of fragility functions for discrete tephra fall impacts to electricity supply, water supply, wastewater and transport networks. Although beyond the scope of this paper, if used in conjunction with fragility functions for other volcanic hazards, the 

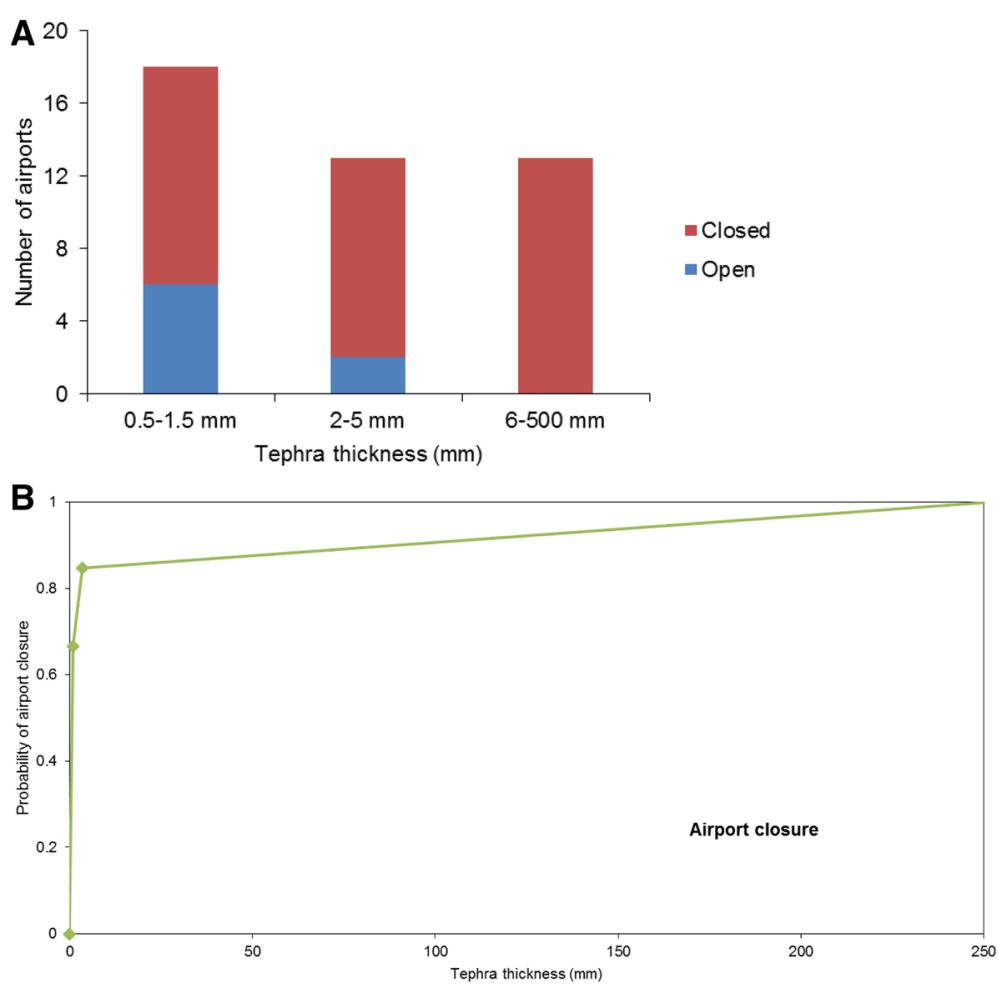

Fig. 10 Airport ash impact histogram and fragility functions. a Histogram of available post-eruption impact data classified by IS for 0.5-1.5, 2-5, and 6-500 mm tephra thickness bins. b Derived fragility functions for airport closure showing probability of equalling or exceeding each IS vs tephra thickness

fragility functions for tephra fall present an opportunity for studying the consequences of multiple hazards on critical infrastructure networks and cascading effects. Source data for the functions are primarily from posteruption impact assessments supplemented by experimental data. We applied our expert judgement guidelines as data was scarce in all cases. The resulting functions give the probability of an infrastructure site being equal to or exceeding one of four impact states as a function of tephra thickness.

The derived fragility functions are a first attempt at quantifying the vulnerability of critical infrastructure sectors to tephra fall. As such, these functions are appropriate for volcanic risk assessments provided the documented assumptions and limitations are fully understood. We envisage these fragility functions will be updated with new post-eruption impact data, experimental data and expert judgment.

\section{Recommendations}

We recommend volcanic impact scientists adopt the method and framework presented here as a standard approach for deriving and updating fragility and vulnerability functions for critical infrastructure sectors impacted by volcanic hazards. Fragility and vulnerability functions are the next step to contribute towards robust probabilistic volcanic risk assessments; essential for the successful management of volcanic risk.

To derive new, and update existing, fragility and vulnerability functions, high quality vulnerability data are required. Table 7 shows that for the majority of the critical infrastructure considered here, data quality is average (C) to below average (D). There are no infrastructure sectors that have vulnerability data which can be classified as high quality (A). This indicates that while there are data available to derive functions, additional research is required to improve data quality and quantity. A particular focus should be the systematic collection and central archiving of additional post-eruption impact data as this provides real-world vulnerability data. There also needs to be a continued focus on laboratory experiments to improve the understanding specific component vulnerabilities.

The fragility functions presented in this manuscript are based on currently available data and should be reviewed and updated when new vulnerability data becomes available. New vulnerability data will assist the understanding of how each infrastructure type is connected with others, which is critical for fully addressing problems (Sword-Daniels et al. 2015). We suggest a similar approach to Blake (2016), in that to understand interdependent effects effectively, it may be appropriate to initially direct vulnerability research towards fully 
understanding the bi-directional effects between two common interconnected systems such as transportation and electricity (e.g. Fotouhi et al. 2017). Additionally, new vulnerability data will improve knowledge on the cumulative effects of multiple hazards - important for disaster risk reduction measures. One approach to studying impacts on infrastructure from multiple hazards is through scenario development, which can also investigate cascading effects for society. Zuccaro et al. (2008) demonstrate that once a range of scenarios are established, stochastic models can be developed to find a sub-set of permutations and combinations of possible effects (Zuccaro et al. 2008, Blake 2016). In the coming years we anticipate that the quality of vulnerability data will increase across the board resulting in high quality functions for multiple volcanic hazards and all critical infrastructure sectors.

\section{Additional files}

Additional file 1: Derived fragility function equations. (DOCX $22 \mathrm{~kb}$ )

Additional file 2: Infrastructure sector vulnerable components and key knowledge gaps. (DOCX $32 \mathrm{~kb}$ )

\section{Abbreviations}

CDFs: Cumulative distribution functions; HEP : Hydroelectric power; HIM: Hazard intensity metric; HV: High voltage; HVAC: Heating, ventilation and air conditioning; IM: Impact metric; IS: Impact state; PDC: Pyroclastic density current; UNISDR: United Nations International Strategy for Disaster Reduction

\section{Acknowledgements}

We gratefully acknowledge funding support from the DEVORA project (funded by the Earthquake Commission, Auckland Council and Ministry of Business, Innovation and Employment) (GW, TMW, NID, DMB), Natural Hazard Research Platform Research Contract C05X0907 (TMW, JC), and GNS Science Core Research Funding (NID).

We also gratefully acknowledge the comprehensive and supportive reviews by Dr. Susanna Jenkins and an anonymous reviewer; and the excellent editorial work by Prof Giulio Zuccaro.

\section{Authors' contributions}

All authors planned the research and wrote the manuscript. GW conducted the research and wrote the manuscript, and TMW, NID and JC reviewed the analysis and contributed to interpretation of the results. DB contributed to the transportation data collection and function derivation and made a large contribution to revision the manuscript following review. All authors have read, reviewed and approved the final manuscript.

\section{Competing interests}

The authors declare that they have no competing interests.

\section{Publisher's Note}

Springer Nature remains neutral with regard to jurisdictional claims in published maps and institutional affiliations.

\section{Author details}

'Department of Geological Sciences, University of Canterbury, Private Bag 4800, Christchurch 8140, New Zealand. Present Address: Office of Emergency Management, 2 Havelock Street, West Perth, WA, Australia. ${ }^{3}$ GNS Science, PO Box 30-368, Lower Hutt 5040, New Zealand.
Received: 8 February 2016 Accepted: 30 August 2017

Published online: 18 September 2017

\section{References}

Baker JW. Efficient analytical fragility function fitting using dynamic structural analysis. Earthquake Spectra. 2014;31:579-99.

Barnard S. The vulnerability of New Zealand lifelines infrastructure to ashfall. Christchurch: Dissertation, University of Canterbury; 2009.

Baxter PJ, Boyle R, Cole P, Neri A, Spence RJS, Zuccaro G. The impacts of pyroclastic surges on buildings at the eruption of the Soufrière Hills Montserrat. Bull Volcanol. 2005;67:292-313.

Blake DM. Impacts of volcanic ash on surface transportation networks: considerations for Auckland City, New Zealand. PhD thesis. Christchurch: University of Canterbury; 2016.

Blake DM, Wilson TM, Gomez C. Road marking coverage by volcanic ash: an experimental approach. Environ Earth Sci. 2016;75(20):12.

Blake DM, Wilson TM, Cole JW, Deligne NI, Lindsay JM. Impact of volcanic ash on road and airfield surface skid resistance. Sustainability. 2017a;9(8):1389.

Blake DM, Deligne NI, Wilson TM, Wilson G. Fragility function development for road transportation during volcanic ash fall. J Appl Volcanol. 2017b; (this issue).

Blong RJ. Volcanic hazards: a sourcebook on the effects of eruptions. Sydney: Academic Press; 1984.

Blong RJ. Building damage in Rabaul Papua New Guinea 1994. Bull Volcanol. 2003a;65:43-54.

Blong RJ. A review of damage intensity scales. Nat Hazards. 2003b;29:57-76.

Blong RJ. A new damage index. Nat Hazards. 2003c;30:1-23.

Blong RJ, Grasso P, Jenkins SF, Magill CR, Wilson TM, McMullan K, Kandlbauer J. Estimating building vulnerability to volcanic ash fall for insurance and other purposes. J Appl Volcanol. 2017;6:2.

Bonadonna C. Probabilistic modelling of tephra dispersion. In: Mader HM, Coles SG, Connor CB, Connor $\sqcup$, editors. Statistics in Volcanology. Special publication of IAVCEl. London: Geological Society of London; 2006. p. 243-59.

Brown SK, Loughlin SC, Sparks RSJ, Vye-Brown C, Barclay J, Calder E, Cottrell E, Jolly G, Komorowski J-C, Mandeville C, Newhall C, Palma J, Potter S, Valentine GA. Global volcanic hazards and risk: technical background paper for the global assessment report on disaster risk reduction 2015 GMV IAVCEl; 2015. p. 233.

Calvi GM, Pinho R, Magenes G, Bommer JJ, Restrepo-Vélez LF, Crowley H. Development of seismic vulnerability assessment methodologies over the past 30 years. ISET J Earthq Technol. 2006;43:75-104.

Cole JW, Blumenthal E. Evacuate! What an evacuation order given because of a pending volcanic eruption could mean to residents of the Bay of Plenty. Tephra 2004:21:46-52.

Costa A, Macedonio G, Folch A. A three-dimensional Eulerian model for transport and deposition of volcanic ashes. Earth Planet Sci Lett. 2006;241:634-47.

Cottrell E. Global distribution of active volcanoes. In: Papale P, editor. Volcanic hazards risks and disasters. Amsterdam: Elsevier; 2014. p. 1-14.

Daly M, Wilkie D. Auckland engineering lifelines project: stage one final report. In: Auckland Regional Council technical publication no. 112; 1999. p. 417.

Davison CR, Rutke TA. Assessment and characterization of volcanic ash threat to gas turbine engine performance. J Eng Gas Turbines Power. 2014;136:081201.

De Risi R, Jalayer F, De Paola F, lervolino I, Giugni M, Topa ME, Gasparini P. Flood risk assessment for informal settlements. Nat Hazards. 2013;69:1003-32.

Del Negro C, Fortuna L, Herault A, Vicari A. Simulations of the 2004 lava flow at Etna volcano using the magflow cellular automata model. Bull Volcanol. 2008:70:805-12.

Douglas J. Physical vulnerability modelling in natural hazard risk assessment. Nat Hazards Earth Syst Sci. 2007;7:283-8.

Drexler JM, Gledhill AD, Shinoda K, Vasiliev AL, Reddy KM, Sampath S, Padture NP. Jet engine coatings for resisting volcanic ash damage. Adv Mater. 2011; 23:2419-24.

Dunn MG. Operation of gas turbine engines in an environment contaminated with volcanic ash. J Turbomach. 2012;134:1-18.

Engwell SL, Sparks RSJ, Aspinall WP. Quantifying uncertainties in the measurement of tephra fall thickness. J Appl Volcanol. 2013:2:1-12.

Galderisi A, Bonadonna C, Delmonaco G, Ferrara FF, Menoni S, Ceudech A, Biass S, Frischknecht C, Manzella I, Minucci G, Gregg C. Vulnerability assessment and risk mitigation: the case study of Vulcano Island, Italy. In: Margottini C, Canuti P, Sassa K, editors. Landslide science and practice. Volume 7: social and economic impact and policies. Berlin: Springer; 2012.

Fotouhi H, Miller-Hooks E, Moryadee S. Quantifying the resilience of an urban traffic-electric power coupled system. Reliability Eng Syst Saf. 2017;163:79-94. 
Gordon KD, Cole JW, Rosenberg MD, Johnston DM. Effects of volcanic ash on computers and electronic equipment. Nat Hazards. 2005;34:231-62.

Guffanti M, Mayberry GC, Casadevall TJ. Compilation of disruptions to airports by volcanic activity (version 1.0 1944-2006) U.S. Geological Survey open-file report 2007-1256; 2008. p. 31. http://pubs.usgs.gov/of/2007/1256/. Accessed 12 Nov 2014

Guffanti M, Casadevall TJ, Budding K. Encounters of aircraft with volcanic ash clouds; a compilation of known incidents 1953-2009 US geological survey data series 545 ver. 1.0. 12 (plus 14 appendixes including the compilation database). 2010. http://pubs.usgs.gov/ds/545/. Accessed 12 Nov 2014

Hindin E. Treatment of Mount St. Helens volcanic ash suspensions by plain sedimentation coagulation and flocculation. J Am Water Works Assoc. 1981;73:160-4.

Hughes JF, Healy K. Measuring the resilience of transport infrastructure. New Zealand transport agency research report 546. Wellington: New Zealand Transport Agency; 2014

Jenkins S, Spence R. Vulnerability curves for buildings and agriculture. In: Technical report D4.D for EU FP7-ENV project MIA-VITA contract number 211393; 2009

Jenkins S, Komorowski J-C, Baxter P, Spence R, Picquout A, Lavigne F. The Merapi 2010 eruption: an interdisciplinary impact assessment methodology for studying pyroclastic density current dynamics. J Volcanol Geotherm Res. 2013;261:316-29.

Jenkins S, Spence RJS, Fonseca JFBD, Solidum RU, Wilson T. Volcanic risk assessment: quantifying physical vulnerability in the built environment. J Volcanol Geotherm Res. 2014a;276:105-20.

Jenkins S, Wilson T, Magill C, Miller V, Stewart C, Marzocchi W, Boulton M. Volcanic ash fall hazard and risk: technical background paper for the UN-ISDR 2015 global assessment report on disaster risk reduction. Global volcano model and IAVCEI. 2014b. https://www.unisdr.org/we/inform/publications/ 49769. Accessed 12 Nov 2014

Jenkins SF, Phillips JC, Price R, Feloy K, Baxter PJ, Hadmoko DS, de Bélizal E. Developing building-damage scales for lahars: application to Merapi volcano Indonesia. Bull Volcanol. 2015:77(9):1-17.

Johnston DM, Nairn IA (1993) Volcanic impacts report. The impact of two eruption scenarios from the Okataina volcanic Centre New Zealand on the population and infrastructure of the bay of plenty region. Bay of plenty regional council resource planning publication 93/6 153p.

Johnston DM, Stewart C, Leonard G, Hoverd J, Thordarsson T, Cronin S. Impacts of volcanic ash on water supplies in Auckland: part I GNS science report; 2004. p. 83.

Kaye G. RiskScape volcano - a volcanic hazard risk assessment model for RiskScape GNS science report 2007/38; 2007. p. 176

Lallemant D, Kiremidjian A, Burton H. Statistical procedures for developing earthquake damage fragility curves. Earthquake Eng Struct Dynam. 2015;44:1373-89.

Magill C, Wilson T, Okada T. Observations of tephra fall impacts from the 2011 Shinmoedake eruption Japan. Earth Planets Space. 2013;65:677-98.

Maqsood T, Wehner M, Ryu H, Edwards M, Dale K, Miller V. GAR15 Regional vulnerability functions. In: Reporting on the UNISDR/GA SE Asian regional workshop on structural vulnerability models for the GAR global risk assessment Geoscience Australia record 2014/38; 2014. p. 614.

Mas E, Koshimura S, Suppasri A, Matsuoka M, Matsuyama M, Yoshii T, Jimenez C, Yamazaki F, Imamura F. Developing tsunami fragility curves using remote sensing and survey data of the 2010 Chilean tsunami in Dichato. Nat Hazards Earth Syst Sci. 2012;12:2689-97.

Matsuoka R, Susumu L, Sakanishi K. Flashover voltage characteristics of insulators contaminated with volcanic ash. In: NGK insulators Ltd. (Japan) internal report; 1995. p. 6

Mundrey JS. Railway Track Engineering, Fourth Edition. New Delhi: Tata McGraw-Hill Education; 2010. p. 630

Nellis CA, Hendrix KW. Progress report on the investigation of volcanic ash fallout from Mount St. Helens Bonneville power administration laboratory report ERJ-80-47; 1980. p. 44

Patterson D. Future volcanic activity in Taranaki: likely impacts and effects on Taranaki infrastructure and the implications for civil defence and emergency response contingency plans. A report to the Taranaki united council and Taranaki civil Defence committee; 1987. p. 148

Pomonis A, Spence RJS, Baxter J. Risk assessment of residential buildings for an eruption of Furnas volcano, São Miguel, the Azores. J Volcanol Geotherm Res. 1999;92:107-31

Porter K, Kennedy R, Bachman R. Creating fragility functions for performancebased earthquake engineering. Earthquake Spectra. 2007;23:471-89.
Quan Luna B, Blahut J, van Westen CJ, Sterlacchini S, van Asch TWK, Akbas SO. The application of numerical debris flow modelling for the generation of physical vulnerability curves. Nat Hazards Earth Syst Sci. 2011;11:2047-60.

Reese S, Ramsay D. Riskscape: flood fragility methodologies. NIWA technical report: WLG2010-45; 2010. p. 46.

Reese S, Bradley BA, Bind J, Smart G, Power W, Sturman J. Empirical building fragilities from observed damage in the 2009 South Pacific tsunami. Earth Sci Rev. 2011;107(1):156-73.

Rinaldi SM, Peerenboom JP, Kelly TK. Identifying understanding and analyzing critical infrastructure interdependencies. Control Systems IEEE. 2001:21:11-25.

Rossetto T, loannou I, Grant DN (2013) Existing empirical vulnerability and fragility functions: compendium and guide for selection GEM technical report 2013-X GEM foundation Pavia Italy.

Rossetto T, D'Ayala D, loannou I, Meslem A. Evaluation of existing fragility curves. In: Pitilakis K, Crowley H, Kaynia AM, editors. SYNER-G: typology definition and fragility functions for physical elements at seismic risk. Dordrecht: Springer; 2014a.

Rossetto T, loannou I, Grant DN, Maqsood T. Guidelines for empirical vulnerability assessment GEM technical report 2014-X GEM foundation Pavia. 2014b. www.globalquakemodel.org. Accessed 12 Nov 2014.

Schilling S. LAHARZ: GIS programs for automated mapping of lahar-inundation hazard zones. In: US geological survey open-file report 98-638; 1998

Schriever W, Hansen A. Snow loads and strength of small roofs in Canada. For Prod J. 1964;14:129-36.

Shinozaki M, Roberts KA, van de Goor B, Clyne TW. Deposition of ingested volcanic ash on surfaces in the turbine of a small jet engine. Adv Eng Mater. 2013;15:986-94.

Schultz MT, Gouldby BP, Simm JD, Wibowo JL. Beyond the factor of safety: Developing fragility curves to characterize system reliability. U.S. Army Engineer Research and Development Center report No. ERDC-SR-10-1 59p. 2010.

Song W, Hess KU, Damby DE, Wadsworth FB, Lavallée Y, Cimarelli C, Dingwell DB. Fusion characteristics of volcanic ash relevant to aviation hazards. Geophys Res Lett. 2014;41:2326-33.

Spence RJS, Pomonis A, Baxter PJ, Coburn AW, White M, Dayrit M. Building damage caused by the mount Pinatubo eruption of June 15 1991. In: Newhall CG, Punongbayan RS, editors. Fire and mud: eruptions and lahars of mount Pinatubo Philippines. Quezon City: Philippine Institute of Volcanology and Seismology; 1996.

Spence RJS, Zuccaro G, Petrazzuoli S, Baxter PJ. Resistance of buildings to pyroclastic flows: analytical and experimental studies and their application to Vesuvius. Nat Hazards Rev. 2004;5:48-59.

Spence RJS, Kelman I, Baxter PJ, Zuccaro G, Petrazzuoli S. Residential building and occupant vulnerability to tephra fall. Nat Hazards Earth Syst Sci. 2005;5:477-94.

Spence RJS, Kelman I, Brown A, Toyos G, Purser D, Baxter PJ. Residential building and occupant vulnerability to pyroclastic density currents in explosive eruptions. Nat Hazards Earth Syst Sci. 2007;7:219-30

Stewart C, Johnston DM, Leonard G, Horwell CJ, Thordarson T, Cronin S. Contamination of water supplies by volcanic ashfall: a literature review and simple impact modelling. J Volcanol Geotherm Res. 2006;158:296-306.

Stewart C, Wilson TM, Leonard GS, Johnston DM, Cole JW. Volcanic hazards and water shortages. In: Briggs AC, editor. Water shortages: environmental economic and social impacts. New York: Nova Publishing; 2010. p. 105-24.

Sword-Daniels VL, Rossetto T, Wilson TM, Sargeant S. Interdependence and dynamics of essential services in an extensive risk context: a case study in Montserrat, West Indies. Nat Hazards Earth Syst Sci. 2015;15:947-61.

Tarbotton C, Dall'Osso F, Dominey-Howes D, Goff J. The use of empirical vulnerability functions to assess the response of buildings to tsunami impact: comparative review and summary of best practice. Earth Sci Rev. 2015;142:120-34.

Totschnig R, Sedlacek W, Fuchs S. A quantitative vulnerability function for fluvial sediment transport. Nat Hazards. 2011:58:681-703.

Valentine GA. Damage to structures by pyroclastic flows and surges, inferred from nuclear weapons effects. J Volcanol Geotherm Res. 1998;87:117-40.

Wadge $G$. Assessing the pyroclastic flow hazards from dome collapse at Soufriere Hills volcano Montserrat. In: Thordarson T, Self S, Larsen G, Rowland SK, Höskuldsson Á, editors. Studies in Volcanology: the legacy of George Walker. Special publication of IAVCEI. London: Geological Society of London; 2009. p. 211-24.

Wardman J, Wilson T, Bodger PS, Cole JW, Stewart C. Potential impacts from tephra fall to electric power systems: a review and mitigation strategies. Bull Volcanol. 2012b;74:2221-41. 
Wardman J, Sword-Daniels V, Stewart C, Wilson T. Impact assessment of the may 2010 eruption of Pacaya volcano Guatemala GNS science report. 2012/09; 2012a. p. 90

Wardman JB, Hardie SR, Wilson TM, Bodger PS. Influence of volcanic ash contamination on the flashover voltage of HVAC outdoor suspension insulators. IEEE Trans Dielectr Electr Insul. 2014;21(3):1189-97.

White J, Stewart C, Wareham D, Wilson T. Treatment of volcanic ashcontaminated surface waters through the optimisation of physical and chemical processes GNS science report; 2011. p. 34.

Wilson G, Wilson T, Cole J, Oze C. Vulnerability of laptop computers to volcanic ash and gas. Nat Hazards. 2012b;63:711-36.

Wilson G, Wilson T, Deligne NI, Cole JW. Volcanic hazard impacts to critical infrastructure: a review. J Volcanol Geotherm Res. 2014;286:148-82.

Wilson T, Stewart C, Sword-Daniels V, Leonard G, Johnston DM, Cole JW, Wardman J, Wilson G, Barnard S. Volcanic ash impacts on critical infrastructure. Phys Chem Earth. 2012a;45:5-23.

Zorn E, Walter T. Influence of volcanic tephra on photovoltaic (PV)-modules: an experimental study with application to the 2010 Eyjafjallajökull eruption Iceland. J Appl Volcanol. 2016;5(1):2.

Zuccaro G, Cacace F, Spence RJS, Baxter PJ. Impact of explosive eruption scenarios at Vesuvius. J Volcanol Geotherm Res. 2008;178:416-53.

Zuccaro G, De Gregorio D. Time and space dependency in impact damage evaluation of a sub-Plinian eruption at mount Vesuvius. Nat Hazards. 2013;68:1399-423.

\section{Submit your manuscript to a SpringerOpen ${ }^{\circ}$ journal and benefit from:}

- Convenient online submission

- Rigorous peer review

- Open access: articles freely available online

- High visibility within the field

- Retaining the copyright to your article

Submit your next manuscript at $\gg$ springeropen.com 